\title{
Macroeconomic Models and the Yield Curve: An Assessment of the Fit
}

\author{
Jagjit S. Chadha and Sean Holly
}

May 2006

CWPE 0640 


\title{
Macroeconomic Models and the Yield Curve: An assessment of the fit*
}

\author{
Jagjit S. Chadha \\ BNP Paribas and University of Brunel ${ }^{\dagger}$ \\ Sean Holly \\ University of Cambridge ${ }^{\ddagger}$
}

18th January 2006

\begin{abstract}
Many have questioned the empirical relevance of the Calvo-Yun model. This paper appends three widely-studied macroeconomic models (CalvoYun, Hybrid and Svensson) with forward rate curves. We back out from observations on the yield curve the underlying macroeconomic model that most closely matches the level, slope and curvature of the yield curve. With each model we trace the response of the yield curve to macroeconomic shocks. We assess the fit of each model with the observed behaviour in forward rates. We find limited support for Calvo-Yun model in terms of fit with the observed yield curve but we find some support for each of the Hybrid and Svensson models. We conclude that macroeconomic persistence seems to be priced into the yield curve.
\end{abstract}

Keywords: Macromodels, Yield Curve, Persistence

JEL-Classification: E43, E44, E47.

\section{Introduction}

Many have questioned the empirical relevance of the Calvo-Yun optimizing model (see, for example, Rudd and Whelan, 2005). This paper examines the

*Acknowledgements: This work draws upon joint work with Charles Nolan and Peter Macmillan. Jagjit Chadha was visiting the Faculty of Economics at Cambridge while this paper was in its infancy. We are grateful for comments from seminar participants at the Centre for Dynamic Macroeconomic Analysis at the University of St Andrews, the University of Brunel and the University of Kent and the Central Bank of Iceland.

$\dagger_{10}$ Harewood Avenue, Marylebone, London NW1 6AA. E-mail: jagjit.chadha@bnpparibas.com. Research Professor at Brunel University and Fellow of the Centre for International Macroeconomics and Finance at Cambridge University.

$\ddagger$ Faculty of Economics, Austin Robinson Building, Sidgwick Avenue, University of Cambridge, Cambridge CB3 9DD, UK. E-mail: Sean.Holly@econ.cam.ac.uk. 
relationship between the yield curve and the macroeconomy using three models that have been widely used to study problems of optimal monetary policy (see, for example, Taylor, 1999 and Bernanke et al, 1999). These models can be derived from intertemporal optimization by households and firms with imperfect competition in goods markets, nominal rigidities arising from sticky prices and timing conventions. We use these models to solve for the yield curve (see, for example, Ellingsen and Söderstrom, 2001) and examine their ability to replicate three features of the curve - the level, slope and curvature - calculated from historical data. ${ }^{1}$ Our main results suggest that a model that is backward looking in prices and output does best. A model which is entirely forward looking does particularly badly. ${ }^{2}$

The term structure is an important conduit for the transmission of monetary policy to output and inflation. Understanding the yield curve is helpful for both market participants and the monetary authorities since yield curves can provide useful information about underlying expectations of inflation and output over a number of different horizons. Financial economists typically make use of factor models. For example, Knez, Litterman, and Scheinkman (1994), Duffie and Kan (1996), and Dai and Singleton (2000) all consider models in which a handful of unobserved factors explain the entire set of yields. By contrast monetary economists attempt to proxy these unobservable factors by macroeconomic conditions (Ang and Piazzesi, 2003 and Piazzesi, 2005). For example, Diebold et al (2005) argue that a joint macro-finance research strategy is likely to provide the most comprehensive understanding of the term structure. Macroeconomists see the short term interest rate as a policy instrument that the Central Bank uses to pursue objectives concerning the price level and output. Financial economists in turn will see the policy rate as a crucial building block for the whole term structure since each yield at different maturities will be a risk adjusted average of future expected short term rates. Macroeconomics can contribute by providing the basis upon which the Central Bank set interest rates. We add to this literature by examining how three stylised macroeconomic models, widely used in macroeconomic theory, can replicate key features of the term structure. ${ }^{3}$

We assess the fit of each model in terms of the behaviour of the modelconsistent yield curve implied by each of the three macroeconomic models and the actual behaviour of the yield curve. As there is a literature that draws attention to the extent to which the yield curve can be informative about future output and inflation movements (Estrella and Hardouvelis, 1991, and Estrella and Mishkin,1997) we also examine the ability of the artificial (or model consistent) yield curve to predict output and inflation dynamics. In this paper, we show that the predictive capabilities of the yield curve seem to stem from

\footnotetext{
${ }^{1}$ Modern approaches to the study of the yield curve stress the need to focus on these aspects (see Bakaert et al, 2004).

${ }^{2}$ Our results mirror recent research by Rudd and Whelan (2005) that has surveyed and cast considerable doubt on the extent to which purely forward-looking rational expectation sticky price models can match the data. The behaviour of the yield curve can thus be thought of as a diagnostic on the implicit macroeconomic model used by the bond markets.

${ }^{3}$ Rudebusch and $\mathrm{Wu}(2004)$ provide a recent important example of evaluating the correct macroeconomic model to use when understanding the yield curve.
} 
the markets' forward-looking expectations of how the monetary authority will use the short term interest rate to stabilise incipient, or pipeline, inflation and output.

The relationship between the volatility of the short and long term interest rate has also been of continuing interest to economists. In a seminal paper, Shiller (1979) drew attention to an important implication of the expectations model of the term structure. Where the long term interest rate is the average of a stream of future expected short rates, the smoothing that this implies should provide limits on the volatility of the long rate. However, Shiller pointed out there appears to be excess volatility in long rates when the data is examined. To some extent, this problem persists in our analysis, as it looks quite difficult to replicate the term structure of volatility with completely forward-looking behaviour. By using a model in which shocks are amplified by an endogenous persistence mechanism the problem appears somewhat less intractable and in this regard we echo a solution offered by Turnovsky (1989, p. 323), who suggested that increasing the relative importance of persistence shocks would help explain 'the apparent excess volatility of long-term rates'.

Building on the previous two points, this paper also contributes to the literature on persistence of macroeconomic variables and the need to develop models in which amplification and persistence occur (see, Kocherlakota, 2000). To match the observed mean and volatility of the yield curve, the paper suggests that we need models that generate their own persistence. The mechanism is as follows: with little or no internal propagation of shocks future output and inflation can be stabilized without recourse to persistent interest rate responses and hence future interest rates should display limited volatility. As the propagation mechanism becomes more persistent, a shock will create momentum for future pressure on output and on inflation and hence will require some response and volatility in future interest rates.

The paper is organized as follows. In section 2 we set out the models we will analyze and the term structure recursion, section 3 outlines the key stylized facts on macroeconomic data and the yield curve, section 4 explains the way we calibrate and estimate the models, section 4 outlines the basic results, and section 5 draws some conclusions. Annex 1 outlines the relationship between the volatility of interest rates and horizon or maturity and Annex 2 outlines each model in companion form.

\section{Models and the Term Structure}

The general form of the model we consider can be written in terms of a $n \times 1$ vector of variables, $\mathbf{x}_{t}$, in state-space form as:

$$
\tilde{\mathbf{A}}_{0} E_{t} \mathbf{x}_{t+1}=\tilde{\mathbf{A}} \mathbf{x}_{t}+\tilde{\mathbf{B}} i_{t}+\tilde{\mathbf{e}}_{t+1},
$$


where $E$ is the expectations operator. The $n \times n$ matrices $\tilde{\mathbf{A}}_{0}$, and $\tilde{\mathbf{A}}$ capture the dynamics of the model, $\tilde{\mathbf{B}}$ defines the policy rule that ensures the attainment of stability and $\tilde{\mathbf{e}}_{t+1}$ is a $n \times 1$ vector of shocks. Re-writing (2.1) as:

$$
\tilde{\mathbf{A}}_{0}\left[\begin{array}{c}
\mathbf{x}_{1, t+1} \\
E_{t} \mathbf{x}_{2, t+1}
\end{array}\right]=\tilde{\mathbf{A}}\left[\begin{array}{l}
\mathbf{x}_{1, t} \\
\mathbf{x}_{2, t}
\end{array}\right]+\tilde{\mathbf{B}} i_{t}+\tilde{\mathbf{e}}_{t+1}
$$

where the matrix $\mathbf{x}_{t}$ of variables is partitioned into sub-vectors of predetermined, $\mathbf{x}_{1}$, which is $m \times 1$, and jump variables $\mathbf{x}_{2}$, which is $(n-m) \times 1$. We can simplify this form by premultiplying by $\tilde{\mathbf{A}}_{0}^{-1}$ to give $\tilde{\mathbf{A}}_{0}^{-1} \tilde{\mathbf{A}}=\mathbf{A}, \tilde{\mathbf{A}}_{0}^{-1} \tilde{\mathbf{B}}=\mathbf{B}$ and $\tilde{\mathbf{A}}_{0}^{-1} \tilde{\mathbf{e}}_{t+1}=\mathbf{e}_{t+1}$ :

$$
\begin{aligned}
{\left[\begin{array}{c}
\mathbf{x}_{1, t+1} \\
E_{t} \mathbf{x}_{2, t+1}
\end{array}\right] } & =\mathbf{A}\left[\begin{array}{l}
\mathbf{x}_{1, t} \\
\mathbf{x}_{2, t}
\end{array}\right]+\mathbf{B} i_{t}+\mathbf{e}_{t+1} \\
i_{t} & =-\mathbf{F}\left[\begin{array}{c}
\mathbf{x}_{1, t} \\
\mathbf{x}_{2, t}
\end{array}\right]
\end{aligned}
$$

where the policy rate is written as a feedback function from the vector of endogenous variables. If we substitute the rule for the interest rate into the state equation, the state transition matrix becomes $\mathbf{A}-\mathbf{B F}$, and:

$$
\left[\begin{array}{c}
\mathbf{x}_{1, t+1} \\
E_{t} \mathbf{x}_{2, t+1}
\end{array}\right]=[\mathbf{A}-\mathbf{B F}]\left[\begin{array}{c}
\mathbf{x}_{1, t} \\
\mathbf{x}_{2, t}
\end{array}\right]+\mathbf{e}_{t+1} .
$$

Taking a Schur decomposition, following Söderlind (1999), we can write each element of the state equation in terms of two matrices, $\mathbf{C}$ and $\mathbf{D}$ :

$$
\begin{aligned}
& \mathbf{x}_{1, t}=\mathbf{C x}_{2, t-1}+\mathbf{e}_{t}, \\
& \mathbf{x}_{2, t}=\mathbf{D x}_{2, t-1} \\
& =\mathbf{D}\left[\mathbf{C x}_{1, t-1}+\mathbf{e}_{t}\right] \text {. }
\end{aligned}
$$

The general solution for the short-term interest rate will then be as follows: 


$$
\begin{aligned}
i_{t} & =-\left[\begin{array}{ll}
1 & \mathbf{D}
\end{array}\right]\left[\begin{array}{l}
\mathbf{F}_{1} \\
\mathbf{F}_{2}
\end{array}\right] \mathbf{x}_{1, t} \\
& =\mathbf{\Psi} \mathbf{x}_{1, t},
\end{aligned}
$$

where $\mathbf{F}_{1}$ and $\mathbf{F}_{2}$ are conformable partitions of $\mathbf{F}$ with respect to $(\mathbf{2 . 6})$ and (2.7).

Definition 1 The policy function, $\boldsymbol{\Psi}$, is set to ensure that the stabilizable dynamic system described by equation (2.5), produces a stability matrix from $[\mathbf{A}-\mathbf{B F}]$.

\subsection{Term Structure Recursion}

We price interest rates as time invariant functions of the economy's current state (see Ljungqvist and Sargent, 2000). We define the term structure as the collection of yields to maturity for bonds with different maturities:

$$
i_{t}^{n}=\frac{1}{n} \sum_{s=0}^{n-1} i_{t+s \mid t}+\xi_{t}^{n},
$$

and substituting (2.9) into (2.10) gives us the expression for the the interest rate forwards:

$$
i_{t}^{n}=\frac{1}{n}\left(\frac{\mathbf{I}-\mathbf{\Psi}^{n-1}}{\mathbf{I}-\mathbf{\Psi}}\right) \mathbf{x}_{2, t}+\xi_{t}^{n}
$$

For a quarterly model, we solve for $n=8$ and for $n=20$ to give us the pure expectations determined 2-year and 5-year spot rates. As we solve under certainty equivalance, the risk premium is explicitly restricted to zero.

Definition 2 The term structure of interest rates is a function of $\mathbf{x}_{1 t}$ and will be stabilized by the policy function, $\boldsymbol{\Psi}$. 


\subsection{Three Macroeconomic Models}

We take three simple sticky-price macroeconomic models, widely used to study optimal economic policy (Yun, 1996, Svensson, 1999, Amato and Laubach, 2003, Smets and Wouters, 2003 and Woodford, 2003). The models that form the basis for the analysis of this paper is the Calvo-Yun model of forward-looking pricesetting, the so-called hybrid model and the Svensson model, where inflation responds with a two-period lag to monetary policy. The models have a similar structure in so far as aggregate demand is determined by the path of real shortterm interest rates, there is a short trade-off between inflation and output, the money market clears endogenously with respect to a policy rule for interest rates and there is a flex-price equilibrium level of output.

The key difference between these models is the timing conventions that output and inflation follow. In the Calvo-Yun set-up, both key variables are forward-looking, whereas in the hybrid model both variables have backward and forward-looking adjustment paths. In the Svensson model, inflation becomes pre-determined and output adjusts to within period shocks gradually. The models are subject to a variance-covariance matrix of standard shocks to aggregate demand, the mark-up, monetary policy and flex-price output.

\subsubsection{Calvo-Yun}

The key equations in each model are the aggregate demand and supply equations. For the Calvo-Yun model these are as follows:

$$
\begin{gathered}
y_{t}=E_{t} y_{t+1}-\sigma\left(i_{t}-E_{t} \pi_{t+1}\right)+\epsilon_{A, t} \\
\pi_{t}=\beta \pi_{t+1}+\kappa\left(y_{t}-\tilde{y}_{t}\right)+\epsilon_{B, t} \\
m_{t}-p_{t}=y_{t}-\eta i_{t} \\
i_{t}=\phi_{\pi}(1-\rho) \pi_{t}+\phi_{y}(1-\rho) y_{t}+\rho i_{t}+\epsilon_{C, t} \\
\tilde{y}_{t}=\epsilon_{D, t}
\end{gathered}
$$

$y_{t}$ is output, $E_{t} y_{t+1}$ is the expectation at time $\mathrm{t}$ of output in period $t+1$, $i_{t}$ is the short term interest rate, $E_{t} \pi_{t+1}$ expectation at time $\mathrm{t}$ of inflation, in period $t+1, \tilde{y}_{t}$ is capacity output, $m_{t}$ is the money stock and $p_{t}$ is the price level. $\epsilon_{i, t}$ are iid shocks to the $i t h$ equation. ${ }^{4}$

\subsubsection{Hybrid}

A simple ad hoc contruction that allows more gradual adjustment in output and inflation to shocks can be obtained if we allow for habit formation in consumption or other forms of persistence (Makiw and Reiss, 2004). ${ }^{5}$ Equations

\footnotetext{
${ }^{4}$ Note that all variables are written as log-deviations from steady-state.

${ }^{5}$ See, for example, Corrado and Holly (2004).
} 
(2.14-2.16) remain the same but the aggregate output and inflation equations become:

$$
\begin{gathered}
y_{t}=\left(1-\lambda_{b}\right) E_{t} y_{t+1}+\lambda_{b} y_{t-1}-\sigma\left(i_{t}-E_{t} \pi_{t+1}\right)+\epsilon_{A, t} \\
\pi_{t}=\left(1-\lambda_{b}\right) \beta \pi_{t+1}+\lambda_{b} \pi_{t-1}+\kappa\left(y_{t}-\tilde{y}_{t}\right)+\epsilon_{B, t} .
\end{gathered}
$$

\subsubsection{Svensson}

A widely used ad hoc construction to create even more gradual adjustment in output and inflation to shocks follows Svensson (1998). ${ }^{6}$ In this case the aggregate output and inflation equations become:

$$
\begin{gathered}
y_{t}=y_{t-1}-\sigma\left(i_{t-1}-\pi_{t-1}\right)+\epsilon_{A, t} \\
\pi_{t+1}=\pi_{t}+\kappa\left(y_{t}-\tilde{y}_{t}\right)+\epsilon_{B, t} .
\end{gathered}
$$

\section{The Key Facts}

Let us fix some key stylised facts on the economy. Table 1 describes the UK economy, using Hodrick-Prescott filtered data, over the period 1980-2004 (I), and for two late sample sub-periods, 1992-2004 (II) and 1997-2004 (III). For each variable, $x_{t}$, we give the standard deviation of the cycle, $\sigma$, the correlation with output, $\rho_{x, y}$, and the relative standard deviation with respect to the policy rate, $\sigma_{x} / \sigma_{i}$. Inflation and output tend to have a similar level of volatility but one that is lower than that for the interest rate. As one might then expect, two-year and five-year spot interest rates are somewhat more volatile than inflation and output but less volatile than the short rate itself. The yield curve at two years tends to be no more volatile than the two-year spot rate suggesting positive covariation between the policy rate and the two-year spot. But the five year yield curve is somewhat more volatile, which suggests less positive correlation of policy rate with longer term interest rates.

Inflation, policy rates and interest rates are significantly correlated with output in all sub-periods. Except for inflation in the period 1997-2004, this correlation is positive. When significant, the yield curve at two years and five years is negatively correlated with output. The final three rows summarise the yield curve responses in terms of the level, slope and curvature of up to five

${ }^{6}$ Ellingsen and Söderstrom (2001) have previously derived the yield curve from this model and Chadha et al (2005) show how it can explain the shifts in the yield curve on important days of news in the UK. 
years. The level response summarises the response of the individual spot rates at each horizon and the slope results mirror the yield curve results, where the level and slope are respectively positively and negatively related to output. In general there is no relationship between curvature and output. ${ }^{7}$

Table 2 describes the dynamic relationship between the yield spread output and inflation. The rows labelled I, II and III correspond to the data samples defined in Table 1. Both output and inflation are negatively correlated contemporaneously with the two and five-year yield spreads. There is also evidence of significant negative leads from output and inflation to the yield spread up to one year ahead, albeit more so for output. It would also seem that the yield curve has more information for inflation one and two quarters ahead than for output and also a more consistently negative correlation. It would appear that output and inflation, to a lessor extent, negatively lead the yield spread and that the yield spread negatively leads inflation. We shall use the observations developed in this section to assess the explicit implications of the three models developed in Section 2.

\subsection{Estimation and simulation of models}

As shown in Section 2, the models are described as log-linear deviations from a steady-state. This system of linear difference equations can be expressed as a singular dynamic system of the following form:

$$
\check{A} E_{t} y_{t+1}=\check{B} y_{t}+\check{C} \varepsilon_{t} \quad \forall t \geq 0
$$

where $y_{t}$ is the vector of endogenous variables comprising both predetermined and non-predetermined variables including policy rules for the nominal interest rate, $\varepsilon_{t}$ is a vector of exogenous forcing variables, and $\check{A}, \check{B}$ and $\check{C}$ are matrices of fixed, time-invariant, coefficients. $E_{t}$ is the expectations operator conditional on information available at time $t$. King and Watson (1997) demonstrate that if a solution exists and is unique then we may write any such solution in state-space form as follows,

$$
\begin{aligned}
& y_{t}=\Pi s_{t} \\
& s_{t}=M s_{t-1}+G e_{t},
\end{aligned}
$$

where the $s_{t}$ matrix includes the state variables of the model (predetermined variables along with exogenous variables), $e_{t}$ is a vector of shocks to the state variables and $\Pi, M$ and $G$ are coefficient matrices. There are four shocks in $\mathbf{G}$ and the variance-covariance as well as the autocorrelation matrices associated

\footnotetext{
${ }^{7}$ Though we note that in the period 1992-2004, output and curvature look to be negatively correlated and this seems related to the greater volatility of two-year rates at this horizon.
} 
with these shocks are described in Table 3 . The impulse responses of this system are given by:

$$
\begin{aligned}
E_{t} y_{t+k}-E_{t-1} y_{t+k} & =\Pi\left(E_{t} s_{t+k}-E_{t-1} s_{t+k}\right) \\
& =M^{k} G e_{t} .
\end{aligned}
$$

And the variance of the states, $V_{s s}$, is given by:

$$
\operatorname{vec}\left(V_{s s}\right)=(I-M \otimes M)^{-1} \operatorname{vec}\left(G V_{e e} G^{T}\right) .
$$

Definition 3 The variance of the endogenous variables is a positive function of the roots of matrix, $M$, governing the law of motion for the state variables.

We note therefore that larger root in our macroeconomic system will tend to produce greater volatility in endogenous variables, which will include the set of forward curves. Column 1 of Table 3 gives the benchmark calibration parameters for our simulations. As a comparison we refer to King (2002) who calibrates a version of the Calvo-Yun model with the parameters given in column 2 , which are very much standard in this literature. To establish the time series properties of the forcing variables, used to simulate the model, we estimate the key equations of each of the three models using GMM, on UK quarterly data from $1980 .{ }^{8}$ The resulting estimates in the persistence and standard deviations of the shocks to demand, inflation, policy and aggregate supply, $\left\{\epsilon_{i . t}\right\}$, are given in the final column of Table 3 . Given the parameters of the model, we solve this system using the King and Watson (1998) solution algorithm.

\section{Results}

Having solved the models, we assess first the impulse responses of interest rates to the shocks and then assess the fit of the models with respect to the actual data.

\footnotetext{
${ }^{8}$ The note to Table 1 lists the data and sources. The full results are available on request.
} 


\subsection{Impulse Responses}

The solution of the model allows us plot impulse responses. For each shock we show the policy rate responses and five-year yield curve responses.

\subsubsection{Demand Shocks}

Figure 1 shows that the initial policy responses to a $1 \%$ shock to aggregate demand lie in the range of $30-50 \mathrm{Bp}$. The Calvo-Yun model suggests that the initial response of around $30 \mathrm{Bp}$ is the highest, with policy rates returning to their steady-state level at around 5 quarters. The peak response under the hybrid and Svensson model occurs at 2 (some 50Bp) and 3 quarters (some $70 \mathrm{Bp}$ ), respectively but the deviation from steady-state is negligible in the hybrid model after 5 quarters but remains significant in the Svensson model even after 12 quarters. The yield curve responses, shown in Figure 2, mirror the policy responses but with some limited attenuation, to the extent that 5-year rates follow policy rates up. We note that the peak response in the hybrid model and the Svensson model is around 50Bp, which suggests that there is a more persistent response along the yield curve in the case of the Svensson model.

\subsubsection{Mark-up Shocks}

Figure 3 shows that the magnitude of interest responses are significantly larger in the case of mark-up shocks but the dynamics are somewhat similar. The peak response from a $1 \%$ mark-up shock in the Calvo-Yun model is $100 \mathrm{Bp}$ in period 1 , in the hybrid model is around 250Bp in period 2 and just under 200Bp in period 3 in the Svensson model. The responses of the first two models have dissipated after five quarters but the response under the Svensson model remains relatively strong at 16 quarters. Figure 4 shows that again there appears little response in the longer term interest rates under the Calvo-Yun and hybrid models but under the Svensson model, the peak response suggests that long term rates persistently respond by around $50 \mathrm{Bp}$.

\subsubsection{Monetary Policy Shocks}

Figure 5 plots the responses to a monetary policy shock. With the Calvo-Yun model the policy rate moves up around $75 \mathrm{Bp}$ as part of a monetary policy shock and in each subsequent period moves gradually back to base by the fifth quarter. Under hybrid and Svensson models, we observe similar patterns as before with more hump-backed responses. But we observe in both cases some overshooting in interest rates which means that, from Figure 6, the yield curve moves from being downward sloping in the first two to three quarters of a monetary policy shock to upward sloping subsequently. 


\subsubsection{Supply Shocks}

Figure 7 shows that policy rates fall in response to a $1 \%$ positive shock to supply. The Calvo-Yun model shows the smallest first period response followed by the hybrid model and the Svensson model. The yield curve responses, shown in Figure 8, are somewhat more attenuated in all cases and suggest a more persistent response of longer term interest rates to supply shocks than the other shocks, which clearly occurs because the shocks themselves are significantly more persistent in the first place.

\subsubsection{Explanation}

The main results from this section are clear. The less forward looking the model the more drawn out the responses to shocks. The transmission mechanisms in the models are key. In the Calvo-Yun model, the output and inflation are solved forward in the period of any shock and can be stabilised accordingly by appropriate choice of the policy rate. The hybrid model provides a more prolonged response as the transmission mechanism embeds some adjustment in a backward-looking as well as forward-looking manner. The Svensson model incorporates strong pipeline effects as inflation is predetermined and that substantially staggers and prolongs the response of the economy to shocks, the persistence of policy rates and hence of longer term interest rates.

\subsection{Comparison with Data}

In this section we turn to a comparison of the properties of the 3 models with the characteristics of the actual data shown in Table 1. Since the properties for output and inflation are well known in the literature we concentrate on the policy rate and the term structure of interest rates. If we examine the results for the benchmark calibration in Table 4, the correlation between the policy rate and output, shown as $\rho_{y}$, is always positive in the data, but only the Svensson model reproduces this positive effect. The correlation between output and the spot two year and five year long term interest rates is positive in the data, yet the Calvo-Yun model suggests a negative correlation. The correlation between output and the two and five year spread varies in the data but is negative after 1997. The Calvo-Yun model has a strong positive correlation, it is smaller in the Hybrid model and although positive for the two year spread, the Svensson model has an insignificant correlation for the 5 year spread.

For the level of the term structure (the weighted average of the policy rate, and the two year and the five year spot interest rates) the correlation with output is positive in the data. For the models, Calvo-Yun is negative, the Hybrid zero and positive for the Svensson version. The slope, which is essentially the difference between the two year and five year spot rates is negatively correlated with output in the data. The Calvo-Yun model suggests a positive correlation while the Hybrid and Svensson models suggest a negative correlation. Finally 
curvature (the sum of the the policy rate and the five year yield minus twice the two year yield) varies in the data. It is negatively correlated with output for 1992-2004, but not correlated for the full period of 1980-2004. The correlation is negative in all three models, with the largest effect in the Calvo-Yun model and the smallest in the Svensson model.

In terms of the standard deviations of the policy rate and the term structure, the Svensson model tends to be much more volatile than the Hybrid and the Calvo-Yun models. Turning to the ratios of the standard deviation of features of the term structure and the standard deviation of the policy rate, these are always less than one in the data, with the exception of the five year spread in the period 1997-2004. For all three models the relative standard deviations for the 2 year and five year spots are much lower than the data, though the Svensson model has ratios twice those of the Calvo-Yun and Hybrid models. For the two year and five year yield curves the relative standard deviations are highest for the Hybrid and lowest for the Calvo-Yun model. For the slope all three models produce similar results. Finally for curvature, the ratio is highest for the Svensson model and lowest for the Calvo-Yun model.

Overall the Svensson model leads to the closest fit to the data presented in Table 1. Figures 9 and 10 plot the correlations and relative standard deviations of the Benchmark model for Calvo-Yun and for the Svensson model. This simply illustrates how close the Svensson model is to matching the correlations in the model and how it pushes out, to some extent, volatility to the relatively ubiquitous level found in the data.

\subsubsection{Sensitivity Results}

Tables 5 and 6 provide some results when key parameters are varied. In Table 5 the intertemporal elasticity is lowered to 0.1 . This makes output less responsive to the real interest rate and generally increases the volatility of the policy rate as a more rigorous response to disturbances is required with a lower intertemporal elasticity. However, for the Svensson model there is a slight reduction in the volatility of the policy rate. Overall, the lower intertemporal elasticity in the Calvo-Yun model raises the volatility of all components of the term structure. This is also the case for the Hybrid model. However, the results for the Svensson model are more mixed. Volatility increases for the spot forward rates but falls for the spreads, is largely unchanged for the slope, falls for curvature and rises for the level. For the correlation with output, the Calvo-Yun model still has a negative correlation with the 2 year and five year spread, while it remains postive in the Hybrid and Svensson models. In the Svensson model the positive correlation between output and the slope of the term structure becomes negative, and the correlation with curvature insignificant.

In Table 6 a further set of simulations are reported where now added to the lower intertemporal elasticity is a more elastic Phillips curve. In this case, for the Svensson model there is a huge increase in the volatility of the term structure, it approximately doubles for the Hybrid model and increases by a 
quarter for the Calvo-Yun model. Despite the relatively poor performance of the Svensson model in matching the moments of the raw data, the model still captures the positive correlation of the level of the yield curve with output but introduces too much relative volatility in the slope.

For both Tables 7 and 8, we adopt a higher weight on output in the policy rule, akin to a nominal income targeting rule, and for the latter Table we also adopt the parameters for $\sigma$ and $\kappa$ used by Rotemberg and Woodford (1997). The resulting moments suggest rather too much inflation volatility in the case of the Calvo-Yun and Hybrid model and rather too much interest rate volatility compared to output. But again the Calvo-Yun model produces ngative correlation between the output and the level of the term structure.

Finally, in Table 9 we examine the correlation of the yield curve with leads of output and inflation. None of the models capture the negative comtemporaneous correlation between the yield curve and output. But the Hybrid and Svensson models capture the negative leads for inflation. As for inflation, the Hybrid and Svensson models capture the negative comtemporaneous and leads of the yield curve with inflation but the Calvo-Yun model does not.

\subsection{Time Series Properties of model simulations}

Figure 11 plots actual data for the period 1980 to 2004. The top panel shows inflation, the policy rate and output; the bottom panel the policy rate and the five year yield. Figures 12, 13 and 14 plot a segment of the simulated data for each of the three models subject to the same sequence of random shocks. This provides another way of understanding how the different models have different consequences for the term structure of interest rates. In Figure 11 the lower panel suggests that the five year yield often leads the policy rate and there is considerable persistence in both interest rates. For the Calvo-Yun model (Figure 12) the policy rate is much more variable and less persistent than the data. The five year yield is also much smoother than the policy rate compared with the data. A similar picture emerges for the Hybrid model in Figure 13. The policy rate is much less persistent and the five year yield much smoother than the data. Figure 14 shows the results for the Svensson model. Here the model is much more successful at capturing both the persistence of the short and the long rate and the tendency for the five year yield to lead the policy rate.

\subsection{Volatility Term Structure}

The volatility of forward rates should fall with horizon. ${ }^{9}$ A further match for our analysis is therefore the extent to which the models capture the way in which volatility falls in the market-derived forwards. Figure 15 plots the standard deviation of the HP filtered forward rates relative to the HP filtered policy rate. The solid line is the UK data with the forward rates at one to five year maturities

\footnotetext{
${ }^{9}$ Annex 1 outlines a short general proof of this proposition.
} 
on data from 1980 to 2004 . We note that volatility does fall with horizon. But now note that the Calvo-Yun yield curve implies very little volatility relative to the policy rate at any of the horizons. Both the Svensson and to a lessor extent the Hybrid model consistent yield curves move substantially closer to the observed volatility of forward rates, though much remains to be done to capture business cycle volatility at 3-5 years. Finally, note from Table 6 that there is a substantial degree of volatility in interest rates in the Svensson model and we show that if we are prepared to create a highly volatile artificial economy, we can capture the volatility in the term structure. We conclude that increasing the endogenous persistence in the economy is likely to be an important factor in capturing observed interest rate persistence.

\section{Concluding Remarks}

The recent macro-finance literature has attempted to exploit the implications of macroeconomics for the behaviour of the yield curve: to provide identifiable factors and to use yield curve behaviour to identify macroeconomic parameters (see, for example, Piazzzi, 2005, and Rudebusch and Wu, 2004). This paper's clear result is that macroeconomic models need to build in substantially more endogenous persistence if a good mapping to yield curve behaviour is to be found. The results point to the difficulty a purely forward-looking macroeconomic model has in explaining the persistence in the term structure, the lead-lag relationships betweeen interest rates, both short and long, and output and inflation and in the term structure of volatility. When endogenous persistence is incorporated, in a relatively simple manner, we find an marked improvement but also suggest that there is much work to be done in order to amplify model-consistent interest rates and fit a satisfactory macroeconomic model to the data.

A promising route has been suggested by Kozicki and Tinsely (2001) who suggest some elements of learning to amplify interest rate responses. Both Gurkaynak et al (2003) and Rudebusch and Wu (2004) attach an important role to persistent shocks in implicit inflation targets as a mechanism for providing a macro mapping, in a two factor model, back to the yield curve. In our paper, to some extent the persistence that is introduced into the dynamic process for inflation, by incorporating pipeline effects seems to mimic this device in our paper. Our results show that a relatively close mapping to real world macroeconomic data can be generated by reducing the forward-looking element in the determination of inflation. Our key insight is that the rational price of forward rates can also become considerably more volatile. 


\section{References}

[1] Amato, J. and T. Laubach, (2003), "Rule-of-Thumb Behaviour and Monetary Policy", European Economic Review, 47, pp. 791-831.

[2] Ang, A. and M. Piazzesi, (2003), "A No-Arbitrage Vector Autoregression of Term Structure Dynamics with Macroeconomic and Latent Variables", Journal of Monetary Economics, 50, 745-787.

[3] Bakaert, G., S. Cho and A. Moreno, (2004), "New-Keynesian Macroeconomics and the Term Structure", Columbia University mimeo.

[4] Bernanke, B. S., T. Laubach, F. S. Mishkin, and A. S. Posen, (2001), Inflation Targeting: Lessons from the International Experience, Princeton University Press.

[5] Corrado, L. and S. Holly, (2004), "Habit Formation and Interest Rate Smoothing", mimeo, University of Cambridge.

[6] Chadha J. S., P. Macmillan and C. Nolan, (2005), "Independence Day of the 'Old Lady': A Natural Experiment on the Implications of Central Bank Independence", Centre of Dynamic Macroeconomic Analysis mimeo, University of St Andrews.

[7] Dai Q. and K. Singleton, (2000), "Specification Analysis of Affine Term Structure Models", Journal of Finance, 55, 1943-1978.

[8] Diebold, F. X., G. D. Rudebusch and S. B. Aruoba, (2004), "The Macroeconomy and the yield curve: A dynamic latent factor approach", Mimeo.

[9] Duffie, D. and R. Kan, (1996), "A Yield-Factor Model of Interest Rates", Mathematical Finance, 6, 379-406.

[10] Ellingsen, T. and U. Söderström, (2001), "Monetary policy and market interest rates", American Economic Review, 91(5), 1594-1607.

[11] Estrella, A., and G. A. Hardouvelis, (1991), "The Term Structure as a Predictor of Real Economic Activity", Journal of Finance, vol. 46, June, pp. 555-76.

[12] Estrella, A., and F. S. Mishkin, (1997),. "The Predictive Power of the Term Structure of Interest Rates in Europe and the United States: Implications for the European Central Bank", European Economic Review, vol. 41, July, pp. $1375-1401$.

[13] Gurkaynak, R. S., Sack, B., and Swanson E., (2003), "The Excess Sensitivity of Long-Term Interest Rates: Evidence and Implications for Macroeconomic Models", Manuscript, Federal Reserve Board. 
[14] Ljungqvist, L. and Sargent, T. J., (2000), Recursive Macroeconomic Theory, The MIT Press, Cambridge, Massachusetts.

[15] King, R. G. and M. W. Watson, (2002), "The Solution of Singular Linear Difference Systems under Rational Expectations", Computational Economics, 20(1-2), pp. 57-86.

[16] Kocherlakota, N., (2000), "Creating Business Cycles Through Credit Constraints", Federal Reserve Bank of Minneapolis Quarterly Review, 24, pp. 2-10.

[17] Kozicki, S. and P. Tinsley, (2001), "Shifting Endpoints in the Term Structure of Interest Rates", Journal of Monetary Economics, 47, pp. 61352 .

[18] Knez, P., R. Litterman and J. Scheinkman, (1994), "Exploration into Factors Explaining Money Market Returns", Journal of Finance, 49, pp. 1861-1882.

[19] Piazzesi, M., (2005), "Bond Yields and the Federal Reserve", Journal of Political Economy, 113, pp. 311-344.

[20] Rotemberg, J. and M. Woodford (1997), "An Optimization-Based Econometric Model for the Evaluation of Monetary Policy," NBER Macroeconomics Annual, 12: pp.297-346.

[21] Rudd, J. and K. Whelan, (2005), "New Tests of the New-Keynesian Phillips Curve", Journal of Monetary Economics (forthcoming).

[22] Rudebusch, G. D. and T. Wu (2004), "A Macro-Finance Model of the Term Stucture, Monetary Policy and the Economy", mimeo, Federal Reserve Bank of San Francisco.

[23] Shiller, R. J. (1979), "The Volatility of Long Term Interest Rates and Expectations Models of the Term Structure", Journal of Political Economy, 87, December, pp. 1190-1219.

[24] Smets, Frank and Raf Wouters (2003), "An Estimated Dynamic Stochastic General Equilibrium Model of the Euro Area," Journal of.the European Economic Association, 5, pp.1123-1175.

[25] Söderlind, P., (1999), "Solution and Estimation of RE Macromodels with Optimal Policy", European Economic Review, 43, pp. 813-823.

[26] Svensson, L. E. O., (1998), "Inflation Targeting: Some Extensions", Scandinavian Journal of Economics, 101(3), pp. 337-361.

[27] Taylor, J.B., (1999), Monetary Policy Rules, (Editor), University of Chicago Press. 
[28] Turnovsky, S. (1989), "The Term Structure of Interest Rates and the Effects of Macroeconomic Policy", Journal of Money, Credit and Banking, 21, 3, pp. 321-47.

[29] Woodford, M. (2003), Interest and Prices: Foundations of a Theory of Monetary Policy, Princeton University Press.

[30] Wu, T. (2002), "Monetary Policy and the Slope Factors in Empirical Term Structure Estimations," Federal Reserve Bank of San Francisco Working Paper 02-07.

[31] Yun, T. (1996), "Nominal Price Rigidity, Money Supply Endogeneity, and Business Cycles," Journal of Monetary Economics, 1996, 37, pp.345-70. 


\section{Annex 1: Bond Pricing and Volatility}

In this annex, we show that under fairly general conditions the variance of longer horizon bonds falls relative to that of the one period current bond. Let the price of a one-period bond at time $t, p_{1, t}$, be a deterministic function of a standard pricing kernel, $M_{t+1}$ :

$$
p_{1, t}=E_{t}\left(M_{t+1}\right)
$$

where $E_{t}$ is the expectations operator. Let us split up the pricing kernel into a discount factor, $\beta$, and a term that captures the intertemporal rate of substitution between time period, $t$, and $t+1, \lambda_{t+1}^{-1}$, so that we can now write:

$$
p_{1, t}=E_{t} \beta\left(\lambda_{t+1}^{-1}\right) .
$$

Hence the $j$-period bond price can be written as:

$$
p_{j, t}=E_{t}\left(\beta \lambda_{t+1}^{-1}, \lambda_{t+j}^{-1}\right) \quad j=2 \ldots J,
$$

which we can substitute forward to solve in terms of $\lambda_{t+1}^{-1}$ alone,

$$
p_{j, t}=\beta^{j} E_{t}\left(\lambda_{t+1}^{-1}\right) .
$$

Under general conditions, we can write the expectations as a $\log$ function of the current rate of intertemporal substitution, assuming $\lambda_{t+1}^{-1}$ follows a simple $A R(1)$ process, where $0 \leqslant \phi<1$ :

$$
E_{t} \ln \left(\lambda_{t+j}^{-1}\right)=\phi^{j-1} \ln \left(\lambda_{t+1}^{-1}\right)
$$

The price of the $j$-period bond then becomes:

$$
p_{j, t}=\beta^{j} E_{t}\left(\exp -\phi^{j-1} \ln \left(\lambda_{t+1}\right)\right)
$$


Now note that $R_{j, t}=p_{j, t}^{-\frac{1}{j}}$ and so the $j$-period bond yield can be written as:

$$
\ln R_{j, t}=-\frac{1}{j} \ln \beta+\frac{\phi^{j-1}}{j} \ln \left(\lambda_{t+1}\right)
$$

The variance of which is simply given by, which is positive in $\phi$ and negative in $j$ :

$$
\sigma_{\ln R_{j}}^{2}=\left(\frac{\phi^{j-1}}{j}\right)^{2} \sigma_{\ln \lambda_{j}}^{2}
$$

The closed form solution for the variance of the $j$-period bond is then:

$$
\frac{d\left(\sigma_{\ln R_{j}}^{2}\right)}{d j}=2\left(\phi^{2}\right)^{j} \frac{(\ln \phi) j-1}{\phi^{2} j^{3}} \sigma_{\ln \lambda_{j}}^{2}
$$

Definition 4 The variance of the $j$-th period bond increases in the root of the system, $\phi$, and decreases with horizon, $j$. 


\section{Annex 2: Matrices for Models}

Each model can be written in terms of the matrix form given in (2.1). First, the Calvo-Yun model in state-space form has an endogenous state variable matrix $\mathbf{x}_{t}$ defined as follows:

$$
\mathbf{x}_{C-Y, t}^{\prime}=\left[\begin{array}{lllllll}
y_{t} & \pi_{t} & m_{t} & p_{t} & \tilde{y}_{t} & p_{t-1} & y_{t-1}
\end{array}\right]^{\prime},
$$

with the matrices:

$$
\tilde{\mathbf{A}}_{C-Y, 0}=\left[\begin{array}{ccccccc}
1 & \sigma & 0 & 0 & 0 & 0 & 0 \\
0 & \beta & 0 & 0 & 0 & 0 & 0 \\
0 & 0 & 0 & 0 & 0 & 0 & 0 \\
0 & -1 & 0 & 1 & 0 & 0 & 0 \\
0 & 0 & 0 & 0 & 0 & 0 & 0 \\
0 & 0 & 0 & 0 & 0 & 1 & 0 \\
0 & 0 & 0 & 0 & 0 & 0 & 1
\end{array}\right],
$$

and

$$
\tilde{\mathbf{A}}_{C-Y}=\left[\begin{array}{ccccccc}
1 & 0 & 0 & 0 & 0 & 0 & 0 \\
-\kappa & 1 & 0 & 0 & \kappa & 0 & 0 \\
-1 & 0 & 1 & -1 & 0 & 0 & 0 \\
0 & 0 & 0 & 1 & 0 & 0 & 0 \\
0 & 0 & 0 & 0 & 1 & 0 & 0 \\
0 & 0 & 0 & 1 & 0 & 0 & 0 \\
1 & 0 & 0 & 0 & 0 & 0 & 0
\end{array}\right],
$$

with policy matrix desribed as follows:

$$
\mathbf{F}=\left[\begin{array}{lllllll}
\phi_{y} & \phi_{\pi} & \eta & 0 & 0 & 0 & 0
\end{array}\right] .
$$

Under the Hybrid model, the relevant matrices are:

$$
\begin{aligned}
\mathbf{x}_{H, t}^{\prime}= & {\left[\begin{array}{lllllllll}
y_{t} & \pi_{t} & m_{t} & p_{t} & \tilde{y}_{t} & p_{t-1} & y_{t-1} & \pi_{t-1}
\end{array}\right]^{\prime}, } \\
\tilde{\mathbf{A}}_{H, 0} & =\left[\begin{array}{cccccccc}
1-\lambda_{b} & \sigma & 0 & 0 & 0 & 0 & 0 & 0 \\
0 & \left(1-\lambda_{b}\right) \beta & 0 & 0 & 0 & 0 & 0 & 0 \\
0 & 0 & 0 & 0 & 0 & 0 & 0 & 0 \\
0 & -1 & 0 & 1 & 0 & 0 & 0 & 0 \\
0 & 0 & 0 & 0 & 0 & 0 & 0 & 0 \\
0 & 0 & 0 & 0 & 0 & 1 & 0 & 0 \\
0 & 0 & 0 & 0 & 0 & 0 & 1 & 0 \\
0 & 0 & 0 & 0 & 0 & 0 & 0 & 1
\end{array}\right],
\end{aligned}
$$




$$
\tilde{\mathbf{A}}_{H}=\left[\begin{array}{cccccccc}
1 & 0 & 0 & 0 & 0 & 0 & -\lambda_{b} & 0 \\
-\kappa & 1 & 0 & 0 & \kappa & 0 & 0 & -\lambda_{b} \\
-1 & 0 & 1 & -1 & 0 & 0 & 0 & 0 \\
0 & 0 & 0 & 1 & 0 & 0 & 0 & 0 \\
0 & 0 & 0 & 0 & 1 & 0 & 0 & 0 \\
0 & 0 & 0 & 1 & 0 & 0 & 0 & 0 \\
1 & 0 & 0 & 0 & 0 & 0 & 0 & 0 \\
1 & 0 & 0 & 0 & 0 & 0 & 0 & 0
\end{array}\right],
$$

with the policy function maintained.

Finally, under the Svensson model the relevant matrices are given by:

$$
\mathbf{x}_{S, t}^{\prime}=\left[\begin{array}{llllllll}
y_{t} & \pi_{t} & m_{t} & p_{t} & \tilde{y}_{t} & p_{t-1} & y_{t-1} & \pi_{t-1}
\end{array}\right]^{\prime},
$$

$$
\begin{gathered}
\tilde{\mathbf{A}}_{S, 0}=\left[\begin{array}{cccccccc}
0 & 0 & 0 & 0 & 0 & 0 & 0 & 0 \\
0 & 1 & 0 & 0 & 0 & 0 & 0 & 0 \\
0 & 0 & 0 & 0 & 0 & 0 & 0 & 0 \\
0 & -1 & 0 & 1 & 0 & 0 & 0 & 0 \\
0 & 0 & 0 & 0 & 0 & 0 & 0 & 0 \\
0 & 0 & 0 & 0 & 0 & 1 & 0 & 0 \\
0 & 0 & 0 & 0 & 0 & 0 & 1 & 0 \\
0 & 0 & 0 & 0 & 0 & 0 & 0 & 1
\end{array}\right] \\
\tilde{\mathbf{A}}_{S}=\left[\begin{array}{ccccccccc}
1 & 0 & 0 & 0 & 0 & 0 & -1 & -\sigma \\
\kappa & 1 & 0 & 0 & -\kappa & 0 & 0 & 0 \\
-1 & 0 & 1 & -1 & 0 & 0 & 0 & 0 \\
0 & 0 & 0 & 1 & 0 & 0 & 0 & 0 \\
0 & 0 & 0 & 0 & 1 & 0 & 0 & 0 \\
0 & 0 & 0 & 1 & 0 & 0 & 0 & 0 \\
1 & 0 & 0 & 0 & 0 & 0 & 0 & 0 \\
1 & 0 & 0 & 0 & 0 & 0 & 0 & 0
\end{array}\right] .
\end{gathered}
$$


Table 1 - UK macro and yield curve data - 1980-2004

\begin{tabular}{cccccccccc}
\hline \hline & \multicolumn{3}{c}{$1980-2004$} & \multicolumn{3}{c}{$1992-2004$} & \multicolumn{3}{c}{$1997-2004$} \\
\hline$x$ & $s d$ & $\rho_{x, y}$ & $s d_{x} / s d_{i}$ & $s d$ & $\rho_{x, y}$ & $s d_{x} / s d_{i}$ & $s d$ & $\rho_{x, y}$ & $s d_{x} / s d_{i}$ \\
\hline \hline$y_{t}$ & 0.833 & 1.000 & 0.604 & 0.626 & 1.000 & 0.642 & 0.478 & 1.000 & 0.660 \\
$\pi_{t}$ & 0.962 & 0.114 & 0.697 & 0.501 & 0.220 & 0.514 & 0.286 & -0.530 & 0.395 \\
$i_{t}$ & 1.380 & 0.393 & 1.000 & 0.975 & 0.689 & 1.000 & 0.724 & 0.613 & 1.000 \\
$s p_{2, t}$ & 1.087 & 0.393 & 0.788 & 0.901 & 0.753 & 0.924 & 0.638 & 0.452 & 0.881 \\
$s p_{5, t}$ & 0.934 & 0.317 & 0.677 & 0.816 & 0.654 & 0.837 & 0.555 & 0.249 & 0.767 \\
$y c_{2, t}$ & 0.831 & -0.139 & 0.602 & 0.736 & 0.009 & 0.755 & 0.670 & -0.232 & 0.925 \\
$y c_{5, t}$ & 1.064 & -0.236 & 0.771 & 0.920 & -0.150 & 0.944 & 0.866 & -0.353 & 1.196 \\
level & 1.048 & 0.401 & 0.759 & 0.802 & 0.783 & 0.823 & 0.518 & 0.561 & 0.715 \\
slope & 0.814 & -0.334 & 0.590 & 0.667 & -0.433 & 0.684 & 0.658 & -0.456 & 0.909 \\
curvature & 0.762 & -0.027 & 0.522 & 0.677 & -0.223 & 0.694 & 0.605 & 0.010 & 0.836 \\
\hline \hline
\end{tabular}

Note: The data are from ECOWIN, $y_{t}$ is GDP at factor cost (gbr01005), $\pi_{t}$ is the annual change in RPIX (gbr11815), $r_{t}$ is the policy rate (gbr14400), $s p_{2, t}$ is the twoyear benchmark yield (gbr14027), $s p_{5, t}$ is the five-year benchmark yield (gbr14025), $y c_{2, t}$ is the spread between the two-year spot interest rate and the policy rate, $y c_{5, t}$ is the spread between the five-year rate and the policy rate, the level is the weighted average of the policy, two-year and five-year spots, the slope is the five year spread plus curvature, which we measure as the sum of policy rate and five year yield minus twice the two year yield. 
Table 2 - Correlation of Yield spread with current and future inflation and output

\begin{tabular}{ccccccc}
\hline \hline & & $y_{t}$ & $y_{t+1}$ & $y_{t+2}$ & $y_{t+3}$ & $y_{t+4}$ \\
\hline \hline$y c_{2, t}$ & I & -0.139 & -0.063 & 0.059 & 0.137 & 0.138 \\
& II & 0.009 & 0.111 & 0.191 & 0.165 & -0.002 \\
& III & -0.232 & -0.028 & 0.189 & 0.228 & 0.030 \\
$y c_{5, t}$ & I & -0.236 & -0.125 & -0.002 & 0.070 & 0.101 \\
& II & -0.150 & -0.067 & 0.016 & 0.0189 & -0.078 \\
& III & -0.353 & -0.241 & -0.070 & 0.0021 & -0.117 \\
\hline \hline
\end{tabular}

\begin{tabular}{ccccccc}
\hline \hline \multicolumn{1}{c}{} & & $\pi_{t}$ & $\pi_{t+1}$ & $\pi_{t+2}$ & $\pi_{t+3}$ & $\pi_{t+4}$ \\
\hline \hline$y c_{2, t}$ & I & -0.368 & -0.288 & -0.249 & -0.134 & -0.081 \\
& II & -0.378 & -0.388 & -0.310 & -0.088 & 0.025 \\
& III & -0.216 & -0.407 & -0.489 & -0.125 & 0.090 \\
$y c_{5, t}$ & I & -0.394 & -0.348 & -0.303 & -0.213 & -0.157 \\
& II & -0.292 & -0.250 & -0.188 & 0.048 & 0.171 \\
& III & -0.268 & -0.359 & -0.356 & -0.065 & 0.166 \\
\hline
\end{tabular}

Note: The data are HP filtered with lambda set to 1600. Source: see note to Table 1.

$[23]$ 
Table 3 - Calibration parameters

\begin{tabular}{cccc}
\hline \hline & Benchmark & King (2002) & Estimates \\
\hline \hline$\beta$ & 0.99 & 0.99 & \\
$\kappa$ & 0.1 & 0.1 & \\
$\sigma$ & 1.0 & 1.0 & \\
$\lambda_{b}$ & 0.5 (hybrid) & 0.0 & \\
$\eta$ & 7 & 7 & \\
$\phi_{\pi}$ & 1.5 & 1.5 & \\
$\phi_{x}$ & 0.5 & 0.3 & \\
$\rho$ & 0.5 & 0.3 & \\
$\sigma_{a_{t}}$ & 0.015 & 0.01 & $0.01-0.02$ \\
$\rho_{a}$ & 0.214 & $0.33-0.5$ & $0.008-0.42$ \\
$\sigma_{b_{t}}$ & 0.025 & $0-0.01$ & $0.01-0.039$ \\
$\rho_{b}$ & 0.25 & $0-0.8$ & $0.04-0.46$ \\
$\sigma_{c_{t}}$ & 0.06 & $0.0082-0.04$ & $0.05-0.07$ \\
$\rho_{c}$ & 0.115 & 0.3 & $0.11-0.12$ \\
$\sigma_{d_{t}}$ & 0.0072 & 0.0072 & $0.006-0.008$ \\
$\rho_{d}$ & 0.95 & 0.95 & 0.95 \\
\hline \hline
\end{tabular}

Note: The first column gives the parameters used for the baseline calibration. King (2002) is provided as a comparison with the parameters we adopt. Note that $\lambda_{b}$ is 0 except for the baseline calibration of the hybrid model. The estimates of the forcing processes given in the final column are derived from GMM estimation of the system on quarterly UK data (Source: Table 1). In the sensitivity section we alter some of the baseline parameters. 
Table 4 - Calibration Results

\begin{tabular}{cccccccccc}
\hline \multicolumn{1}{c}{ Calvo-Yun } & \multicolumn{3}{c}{ Benchmark } \\
\hline \multicolumn{1}{c}{} & $s d$ & $\rho_{x, y}$ & $s d_{x} / s d_{i}$ & $s d$ & $\rho_{x, y}$ & $s d_{x} / s d_{i}$ & $s d$ & $\rho_{x, y}$ & $s d_{x} / s d_{i}$ \\
\hline \hline$y_{t}$ & 2.096 & 1.000 & 2.063 & 2.158 & 1.000 & 1.621 & 3.669 & 1.000 & 1.232 \\
$\pi_{t}$ & 0.338 & 0.600 & 0.333 & 1.076 & 0.678 & 0.808 & 0.970 & -0.248 & 0.326 \\
$i_{t}$ & 1.016 & -0.904 & 1.000 & 1.331 & -0.258 & 1.000 & 2.979 & 0.152 & 1.000 \\
$s p_{2, t}$ & 0.226 & -0.988 & 0.222 & 0.353 & 0.694 & 0.265 & 1.260 & 0.728 & 0.423 \\
$s p_{5, t}$ & 0.107 & -0.984 & 0.105 & 0.140 & 0.686 & 0.105 & 0.654 & 0.695 & 0.220 \\
$y c_{2, t}$ & 0.804 & 0.864 & 0.791 & 1.230 & 0.478 & 0.924 & 2.701 & 0.182 & 0.907 \\
$y c_{5, t}$ & 0.929 & 0.874 & 0.914 & 1.278 & 0.344 & 0.960 & 2.751 & 0.011 & 0.923 \\
level & 0.442 & -0.941 & 0.435 & 0.533 & -0.001 & 0.400 & 1.259 & 0.476 & 0.423 \\
slope & 0.253 & 0.930 & 0.249 & 0.425 & -0.706 & 0.319 & 1.249 & -0.742 & 0.419 \\
curvature & 0.680 & -0.850 & 0.669 & 1.219 & -0.605 & 0.916 & 2.793 & -0.342 & 0.938 \\
\hline \hline
\end{tabular}

Note: The models were simulated for 10,000 replications and we report the moments of the Hodrick-Prescott filtered data. The results of other filters are available on request. 
Table 5 - Calibration Results

\begin{tabular}{cccccccccc}
\hline \multicolumn{8}{c}{ Low Intertemporal Elasticity $\sigma=0.1$} \\
\hline$x$ & $s d$ & $\rho_{x, y}$ & $s d_{x} / s d_{i}$ & $s d$ & $\rho_{x, y}$ & $s d_{x} / s d_{i}$ & $s d$ & $\rho_{x, y}$ & $s d_{x} / s d_{i}$ \\
\hline \hline$y_{t}$ & 0.884 & 1.000 & 0.499 & 1.159 & 1.000 & 0.588 & 0.577 & 1.000 & 0.258 \\
$\pi_{t}$ & 0.497 & -0.778 & 0.280 & 0.923 & 0.209 & 0.468 & 0.603 & -0.350 & 0.269 \\
$i_{t}$ & 1.773 & -0.684 & 1.000 & 1.971 & -0.406 & 1.000 & 2.239 & 0.073 & 1.000 \\
$s p_{2, t}$ & 0.786 & -0.971 & 0.443 & 0.677 & 0.263 & 0.343 & 1.332 & 0.288 & 0.595 \\
$s p_{5, t}$ & 0.548 & -0.982 & 0.309 & 0.240 & 0.301 & 0.122 & 1.263 & 0.475 & 0.564 \\
$y c_{2, t}$ & 1.232 & 0.366 & 0.695 & 1.764 & 0.554 & 0.895 & 1.633 & 0.135 & 0.729 \\
$y c_{5, t}$ & 1.491 & 0.453 & 0.841 & 1.873 & 0.465 & 0.950 & 2.208 & 0.197 & 0.986 \\
level & 0.964 & -0.870 & 0.544 & 0.842 & -0.217 & 0.427 & 1.384 & 0.276 & 0.618 \\
slope & 0.582 & 0.773 & 0.328 & 0.877 & -0.242 & 0.445 & 1.230 & 0.351 & 0.549 \\
curvature & 0.991 & -0.228 & 0.559 & 1.759 & -0.616 & 0.892 & 1.104 & -0.004 & 0.493 \\
\hline \hline
\end{tabular}


Table 6 - Calibration Results

\begin{tabular}{cccccccccc}
\hline \multicolumn{8}{c}{ Low Intertemporal Elasticity $\sigma=0.1$} \\
\hline \multicolumn{7}{c}{ Calvo-Yun } & \multicolumn{7}{c}{ Hybrid } & \multicolumn{3}{c}{ Svensson } \\
\hline$x$ & $s d$ & $\rho_{x, y}$ & $s d_{x} / s d_{i}$ & $s d$ & $\rho_{x, y}$ & $s d_{x} / s d_{i}$ & $s d$ & $\rho_{x, y}$ & $s d_{x} / s d_{i}$ \\
\hline \hline$y_{t}$ & 1.026 & 1.000 & 0.683 & 1.167 & 1.000 & 0.469 & 1.920 & 1.000 & 0.205 \\
$\pi_{t}$ & 0.847 & -0.757 & 0.480 & 2.020 & 0.302 & 0.812 & 6.128 & -0.221 & 0.653 \\
$i_{t}$ & 1.765 & -0.750 & 1.000 & 2.488 & -0.240 & 1.000 & 9.388 & -0.104 & 1.000 \\
$s p_{2, t}$ & 1.021 & -0.987 & 0.578 & 0.751 & 0.378 & 0.302 & 8.756 & 0.414 & 0.933 \\
$s p_{5, t}$ & 0.703 & -0.983 & 0.398 & 0.282 & 0.370 & 0.113 & 5.700 & 0.904 & 0.607 \\
$y c_{2, t}$ & 1.136 & 0.421 & 0.644 & 2.197 & 0.401 & 0.883 & 5.539 & 0.829 & 0.590 \\
$y c_{5, t}$ & 1.365 & 0.279 & 0.773 & 2.337 & 0.300 & 0.939 & 10.264 & 0.597 & 1.093 \\
level & 1.105 & -0.930 & 0.626 & 1.053 & -0.066 & 0.423 & 6.787 & 0.383 & 0.723 \\
slope & 0.597 & 0.863 & 0.338 & 0.942 & -0.380 & 0.379 & 12.834 & 0.239 & 1.367 \\
curvature & 0.947 & 0.062 & 0.537 & 2.152 & -0.493 & 0.865 & 6.195 & -0.494 & 0.660 \\
\hline \hline
\end{tabular}


Table 7 - Calibration Results

\begin{tabular}{|c|c|c|c|c|c|c|c|c|c|}
\hline & \multicolumn{9}{|c|}{ Low Intertemporal Elasticity $\sigma=0.1$} \\
\hline & \multicolumn{9}{|c|}{ Elastic Phillips Curve Slope $\kappa=0.5$} \\
\hline & \multicolumn{9}{|c|}{ Nominal Income Targetting $\phi_{\pi}=\phi_{x}=1.0$} \\
\hline & \multicolumn{3}{|c|}{ Calvo-Yun } & \multicolumn{3}{|c|}{ Hybrid } & \multicolumn{3}{|c|}{ Svensson } \\
\hline$x$ & $s d$ & $\rho_{x, y}$ & $s d_{x} / s d_{i}$ & $s d$ & $\rho_{x, y}$ & $s d_{x} / s d_{i}$ & $s d$ & $\rho_{x, y}$ & $s d_{x} / s d_{i}$ \\
\hline$y_{t}$ & 0.860 & 1.000 & 0.365 & 1.386 & 1.000 & 0.387 & 0.571 & 1.000 & 0.179 \\
\hline$\pi_{t}$ & 2.014 & -0.843 & 0.856 & 3.745 & 0.542 & 1.046 & 2.086 & -0.611 & 0.655 \\
\hline$i_{t}$ & 2.353 & -0.923 & 1.000 & 3.581 & -0.589 & 1.000 & 3.184 & -0.257 & 1.000 \\
\hline$s p_{2, t}$ & 1.822 & -0.970 & 0.774 & 1.404 & 0.757 & 0.392 & 2.859 & -0.050 & 0.898 \\
\hline$s p_{5, t}$ & 1.406 & -0.948 & 0.598 & 0.433 & 0.833 & 0.121 & 3.201 & 0.136 & 1.005 \\
\hline$y c_{2, t}$ & 1.200 & 0.339 & 0.510 & 3.196 & 0.210 & 0.892 & 2.307 & 0.292 & 0.725 \\
\hline$y c_{5, t}$ & 1.466 & 0.572 & 0.623 & 3.376 & 0.003 & 0.943 & 3.401 & 0.369 & 1.068 \\
\hline level & 1.786 & -0.984 & 0.759 & 1.584 & 0.391 & 0.442 & 2.739 & -0.064 & 0.860 \\
\hline slope & 0.891 & 0.973 & 0.379 & 1.862 & -0.709 & 0.520 & 2.245 & 0.517 & 0.705 \\
\hline curvature & 1.061 & 0.025 & 0.451 & 3.281 & -0.405 & 0.916 & 1.265 & -0.074 & 0.397 \\
\hline
\end{tabular}


Table 8 - Calibration Results

\begin{tabular}{|c|c|c|c|c|c|c|c|c|c|}
\hline & \multicolumn{9}{|c|}{ Intertemporal Elasticity $\sigma=0.03$} \\
\hline & \multicolumn{9}{|c|}{ Phillips Curve Slope $\kappa=0.24$} \\
\hline & \multicolumn{9}{|c|}{ Nominal Income Targetting $\phi_{\pi}=\phi_{x}=1.0$} \\
\hline & \multicolumn{3}{|c|}{ Calvo-Yun } & \multicolumn{3}{|c|}{ Hybrid } & \multicolumn{3}{|c|}{ Svensson } \\
\hline$x$ & $s d$ & $\rho_{x, y}$ & $s d_{x} / s d_{i}$ & $s d$ & $\rho_{x, y}$ & $s d_{x} / s d_{i}$ & $s d$ & $\rho_{x, y}$ & $s d_{x} / s d_{i}$ \\
\hline$y_{t}$ & 0.520 & 1.000 & 0.177 & 0.904 & 1.000 & 0.227 & 0.261 & 1.000 & 0.110 \\
\hline$\pi_{t}$ & 2.335 & -0.915 & 0.793 & 3.292 & 0.103 & 0.827 & 1.019 & -0.457 & 0.430 \\
\hline$i_{t}$ & 2.944 & -0.246 & 1.000 & 3.980 & -0.147 & 1.000 & 2.369 & -0.036 & 1.000 \\
\hline$s p_{2, t}$ & 2.414 & -0.957 & 0.820 & 2.728 & 0.373 & 0.685 & 1.921 & 0.064 & 0.811 \\
\hline$s p_{5, t}$ & 1.881 & -0.948 & 0.639 & 0.947 & 0.612 & 0.238 & 2.299 & 0.172 & 0.970 \\
\hline$y c_{2, t}$ & 1.432 & 0.144 & 0.486 & 2.915 & 0.550 & 0.732 & 1.646 & 0.127 & 0.695 \\
\hline$y c_{5, t}$ & 1.760 & 0.415 & 0.598 & 3.608 & 0.322 & 0.907 & 2.304 & 0.209 & 0.973 \\
\hline level & 2.324 & -0.948 & 0.789 & 2.301 & 0.147 & 0.578 & 1.979 & 0.073 & 0.695 \\
\hline slope & 1.150 & 0.913 & 0.391 & 3.680 & -0.239 & 0.925 & 1.410 & 0.387 & 0.595 \\
\hline curvature & 1.290 & 0.247 & 0.438 & 3.278 & -0.623 & 0.824 & 1.051 & 0.062 & 0.444 \\
\hline
\end{tabular}


Table 9 - Correlation of Yield spread with current and future inflation and output

\begin{tabular}{|c|c|c|c|c|c|c|}
\hline & & $y_{t}$ & $y_{t+1}$ & $y_{t+2}$ & $y_{t+3}$ & $y_{t+4}$ \\
\hline \multirow{3}{*}{$y c_{2, t}$} & Calvo & 0.865 & $\overline{00.292}$ & $\overline{0.014}$ & $\overline{-0.081}$ & $\overline{-0.105}$ \\
\hline & Hybrid & 0.479 & -0.395 & -0.607 & -0.435 & -0.188 \\
\hline & Svensson & 0.185 & -0.185 & -0.366 & -0.403 & -0.353 \\
\hline \multirow[t]{4}{*}{$y c_{5, t}$} & Calvo & 0.874 & 0.295 & 0.017 & -0.076 & -0.104 \\
\hline & Hybrid & 0.345 & -0.510 & -0.664 & -0.440 & -0.165 \\
\hline & Svensson & 0.013 & -0.349 & -0.493 & -0.485 & -0.394 \\
\hline & & $\pi_{t}$ & $\pi_{t+1}$ & $\pi_{t+2}$ & $\pi_{t+3}$ & $\pi_{t+4}$ \\
\hline \multirow[t]{3}{*}{$y c_{2, t}$} & Calvo & 0.784 & 0.248 & -0.002 & "-0.083 & 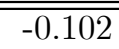 \\
\hline & Hybrid & -0.140 & -0.699 & -0.626 & -0.310 & -0.032 \\
\hline & Svensson & -0.590 & -0.510 & -0.364 & -0.210 & -0.078 \\
\hline \multirow[t]{3}{*}{$y c_{5, t}$} & Calvo & 0.779 & 0.240 & -0.006 & -0.084 & -0.102 \\
\hline & Hybrid & -0.300 & -0.790 & -0.641 & -0.276 & 0.010 \\
\hline & Svensson & -0.655 & -0.509 & -0.313 & -0.128 & -0.018 \\
\hline
\end{tabular}

$[30]$ 
Policy Rate response to $a(t)$ shock

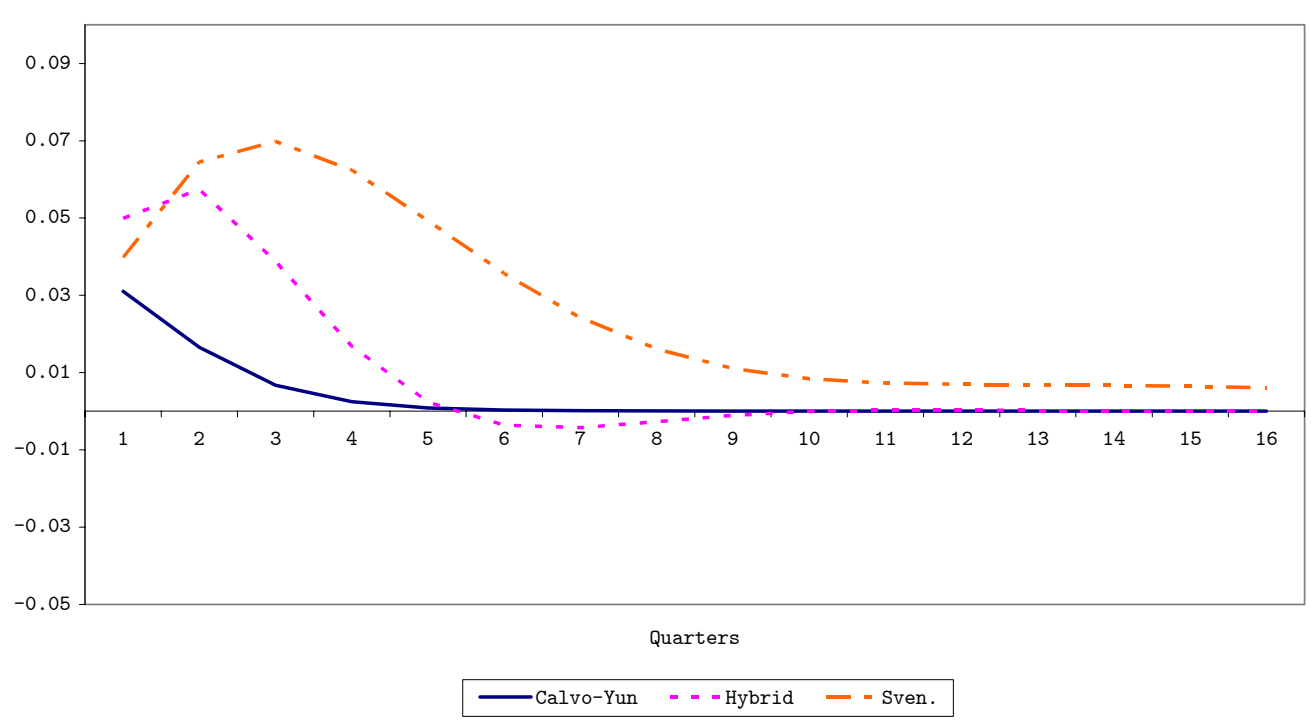

Figure 1: 
Yield Curve response to a(t) shock

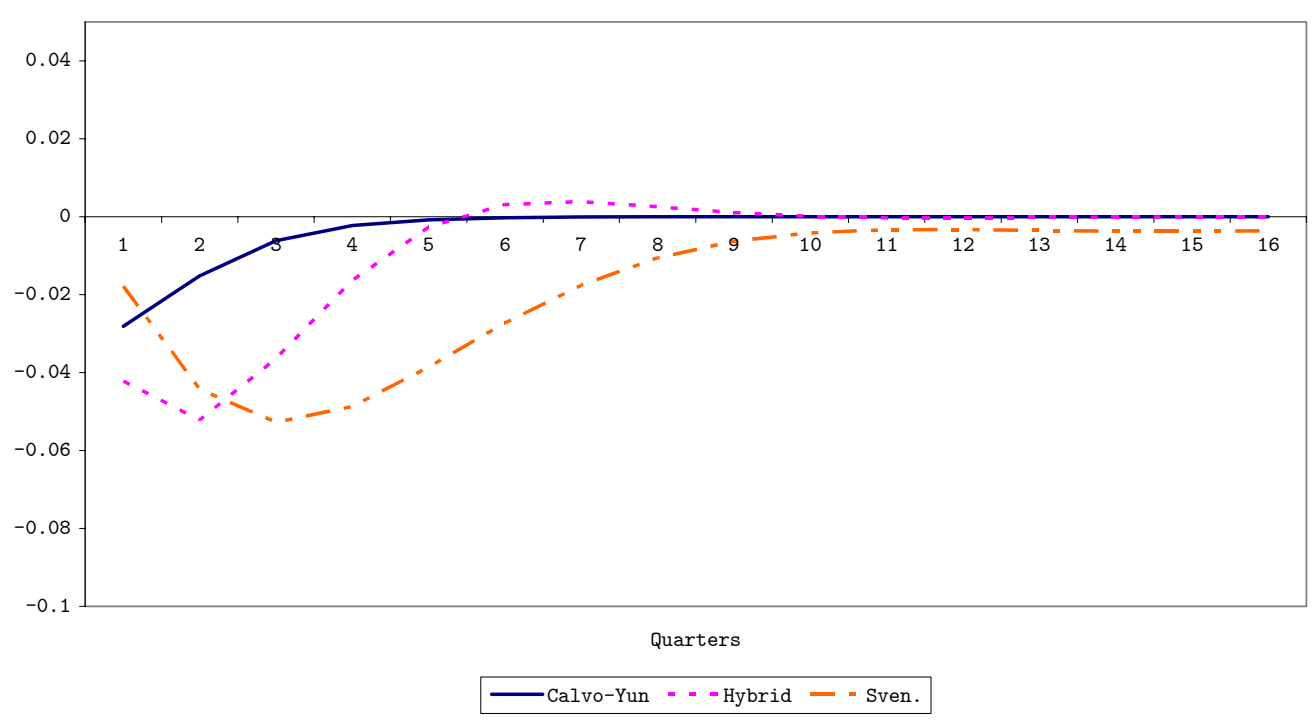

Figure 2: 
Policy Rate response to $b(t)$ shock

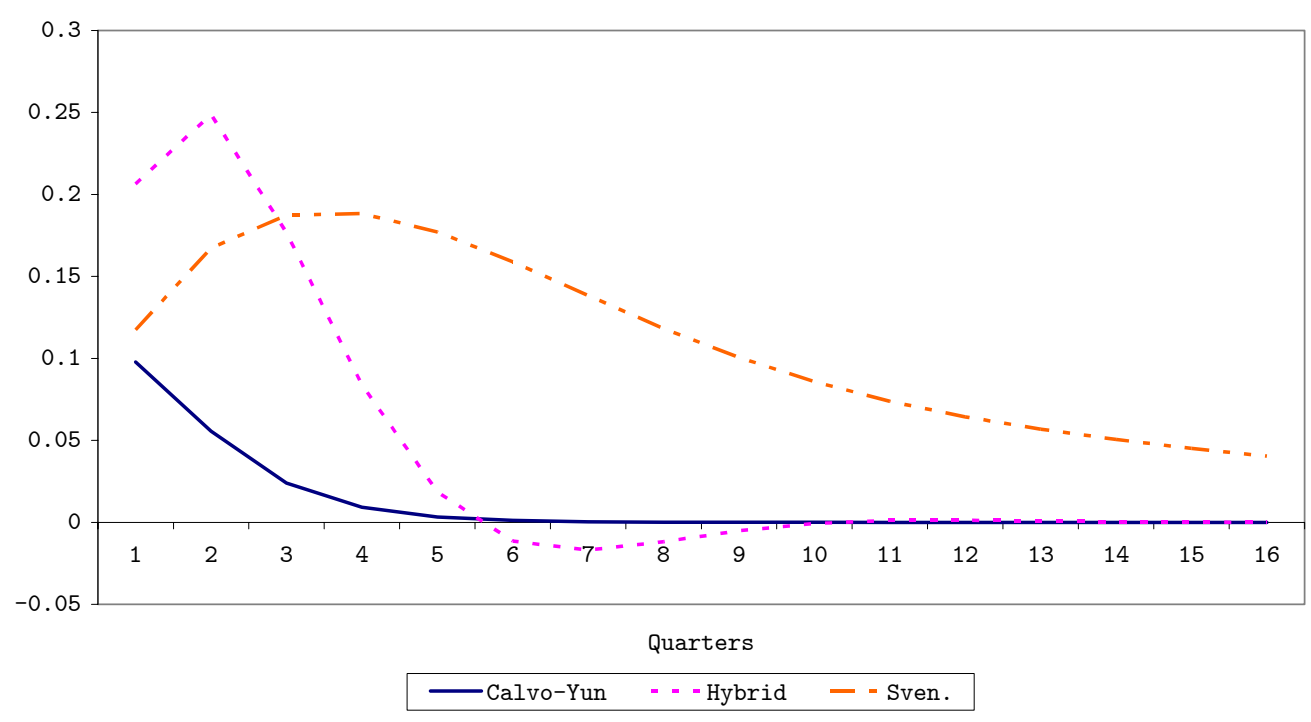

Figure 3: 
Yield Curve response to $b(t)$ shock

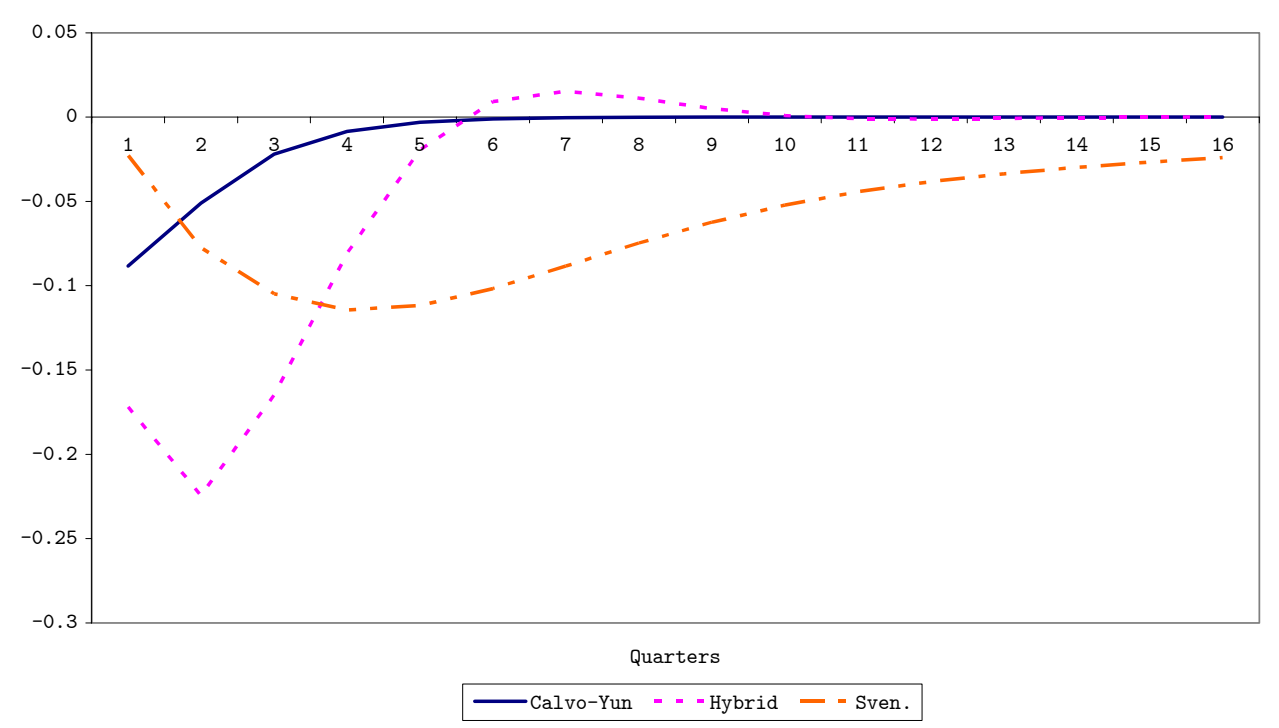

Figure 4: 
Policy Rate response to $c(t)$ shock

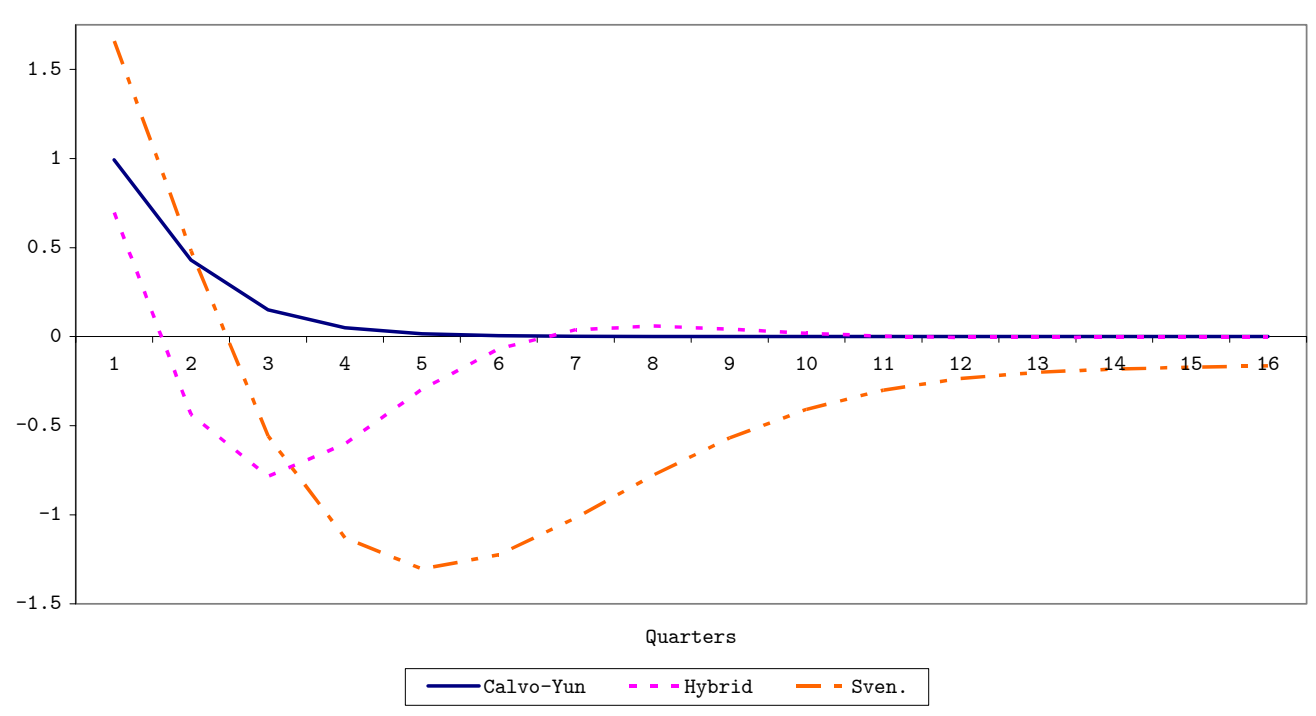

Figure 5: 
Yield Curve response to $c(t)$ shock

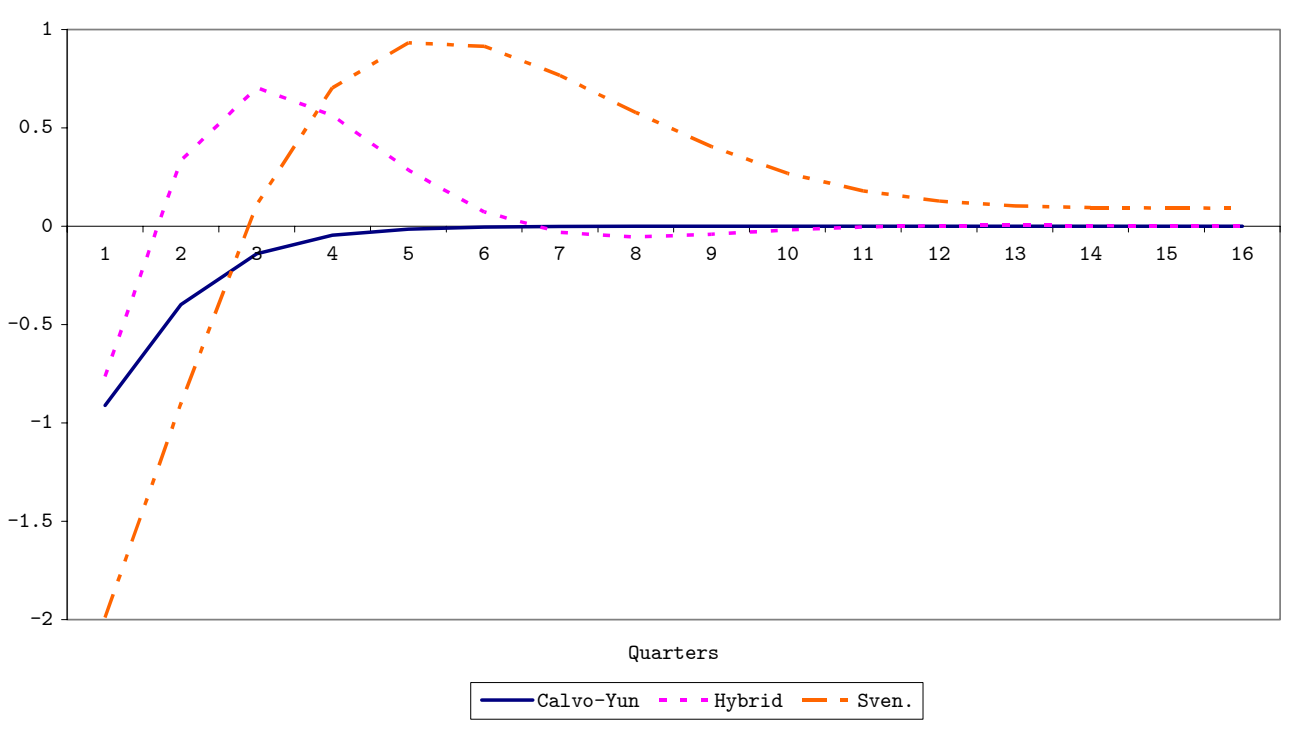

Figure 6: 
Policy Rate response to $d(t)$ shock

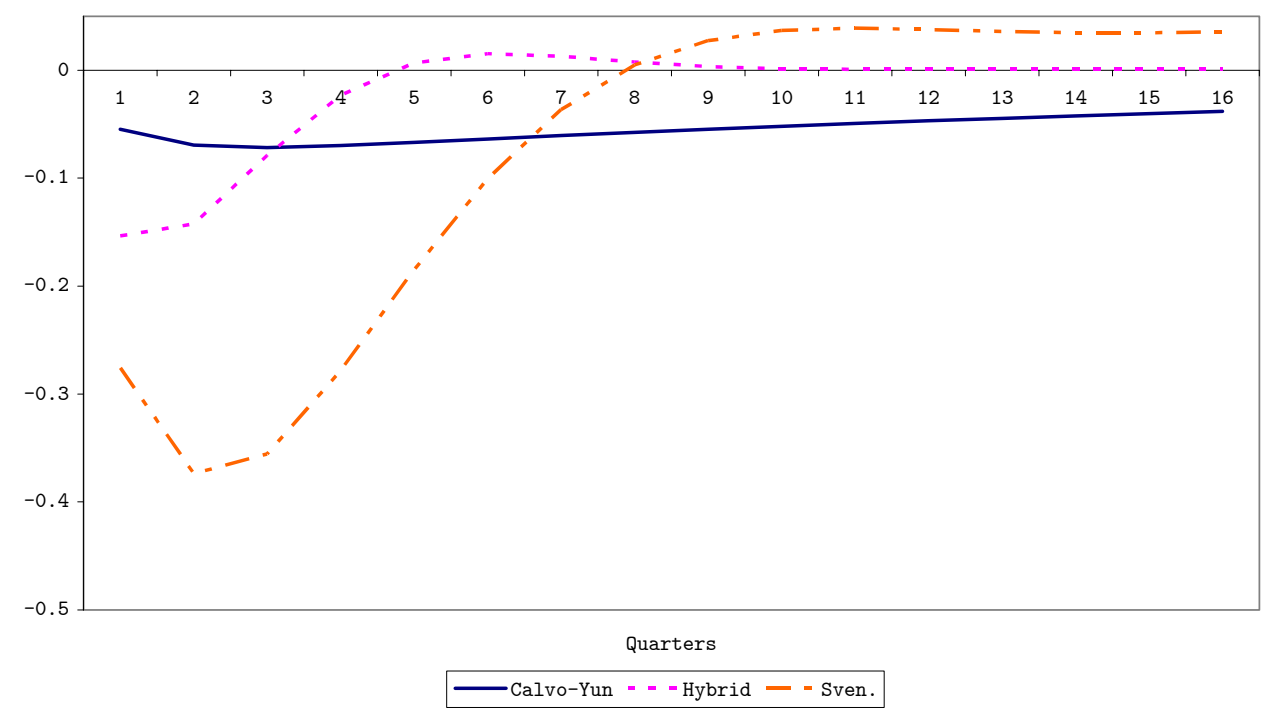

Figure 7: 
Yield Curve response to $d(t)$ shock

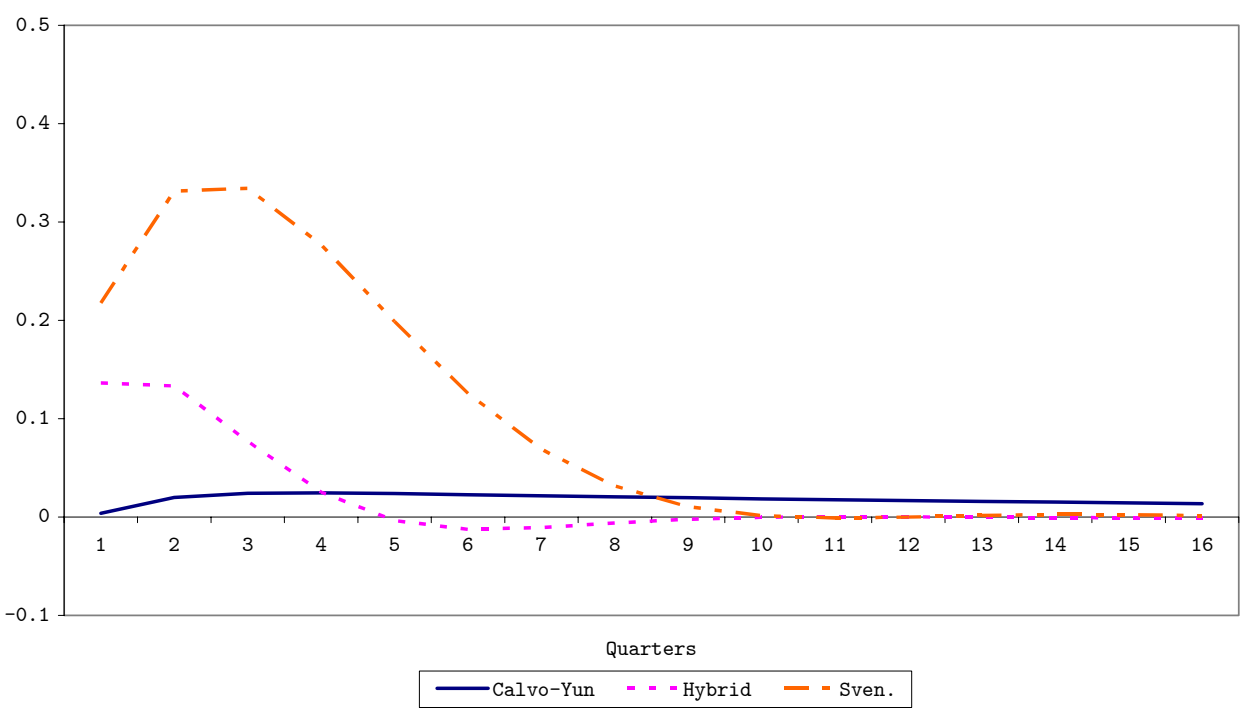

Figure 8:

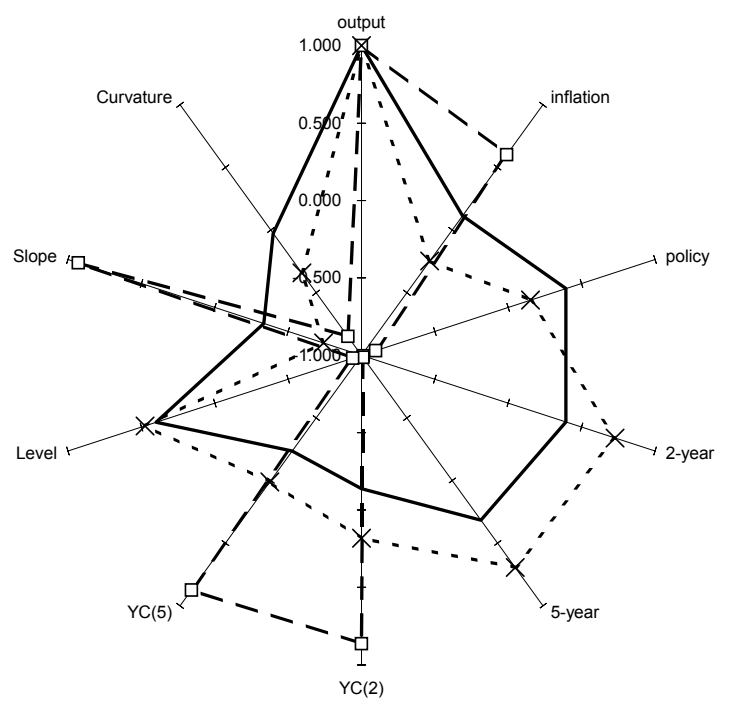




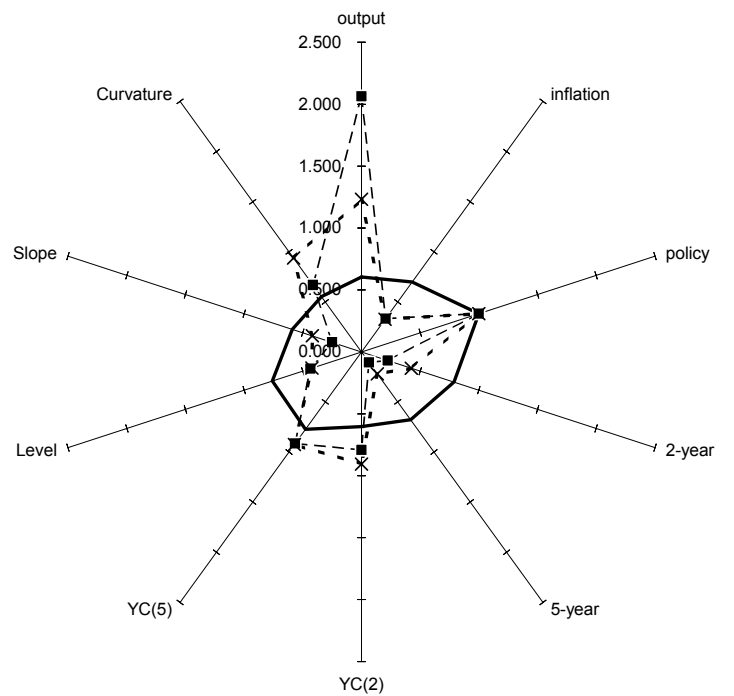
\begin{tabular}{|l|}
\hline -Data \\
\hline$-\dot{-}-$ Calvo-Yun \\
$-\not$ - Sven. \\
\hline
\end{tabular}

Figure 10: 

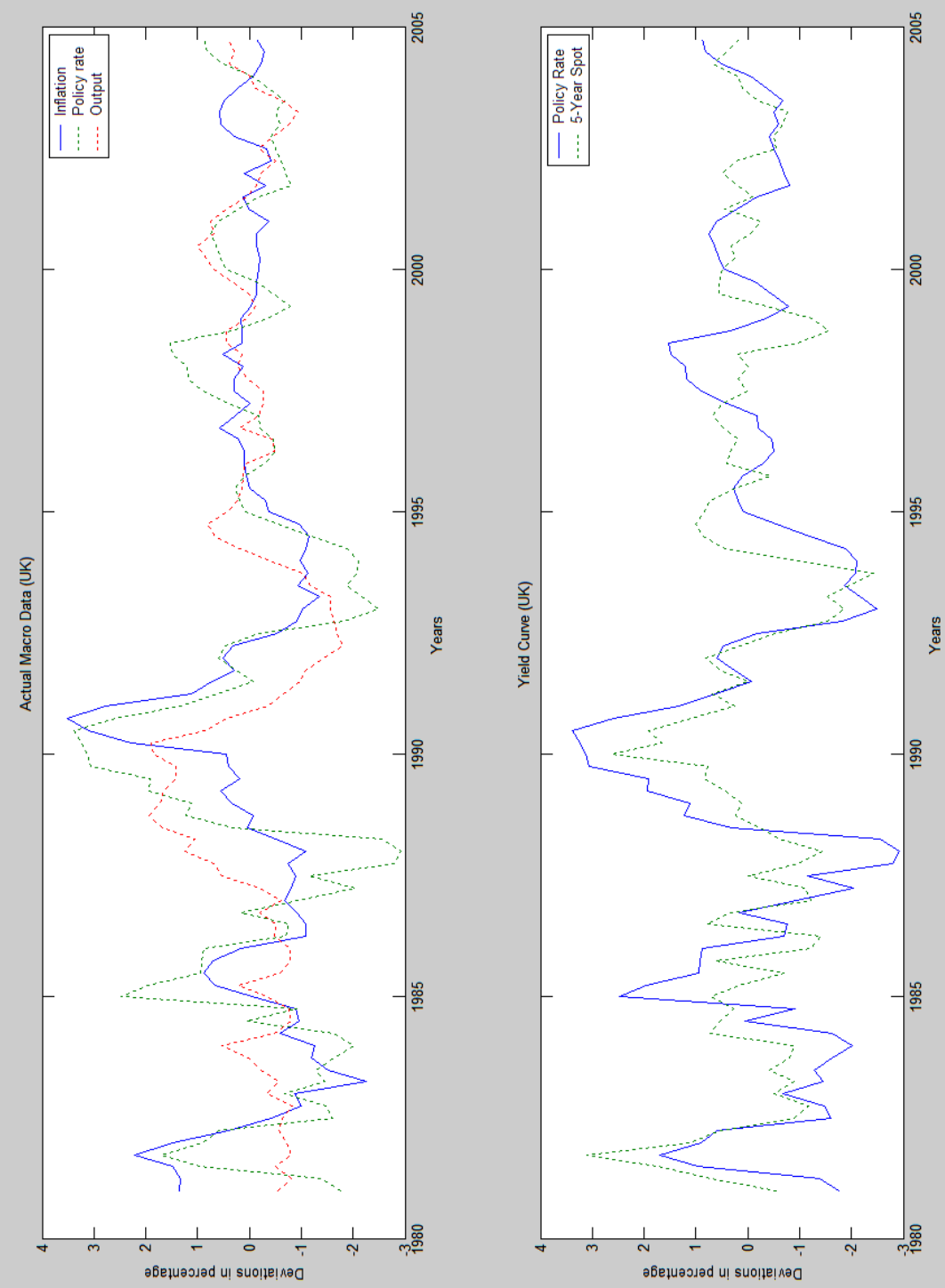

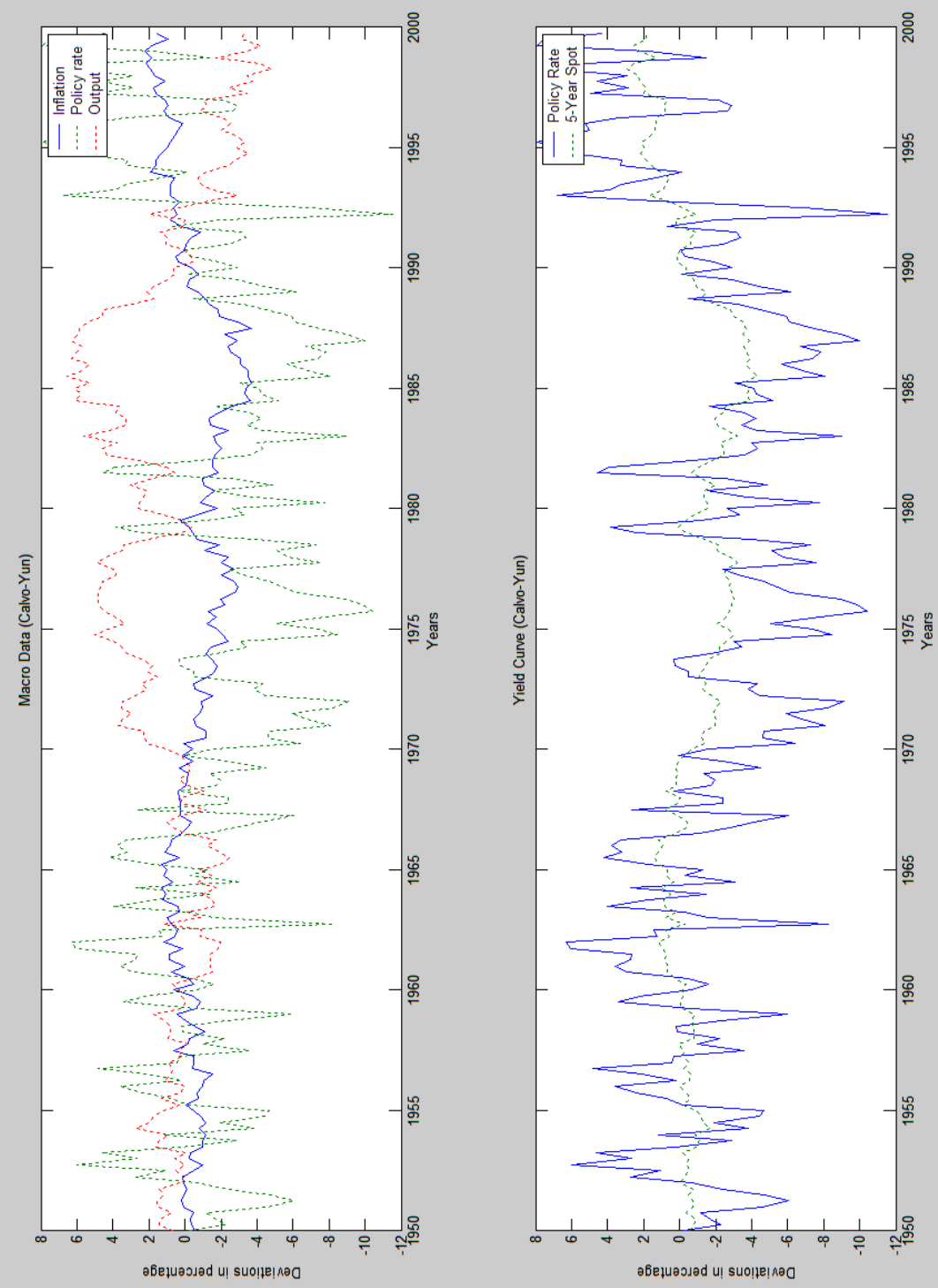

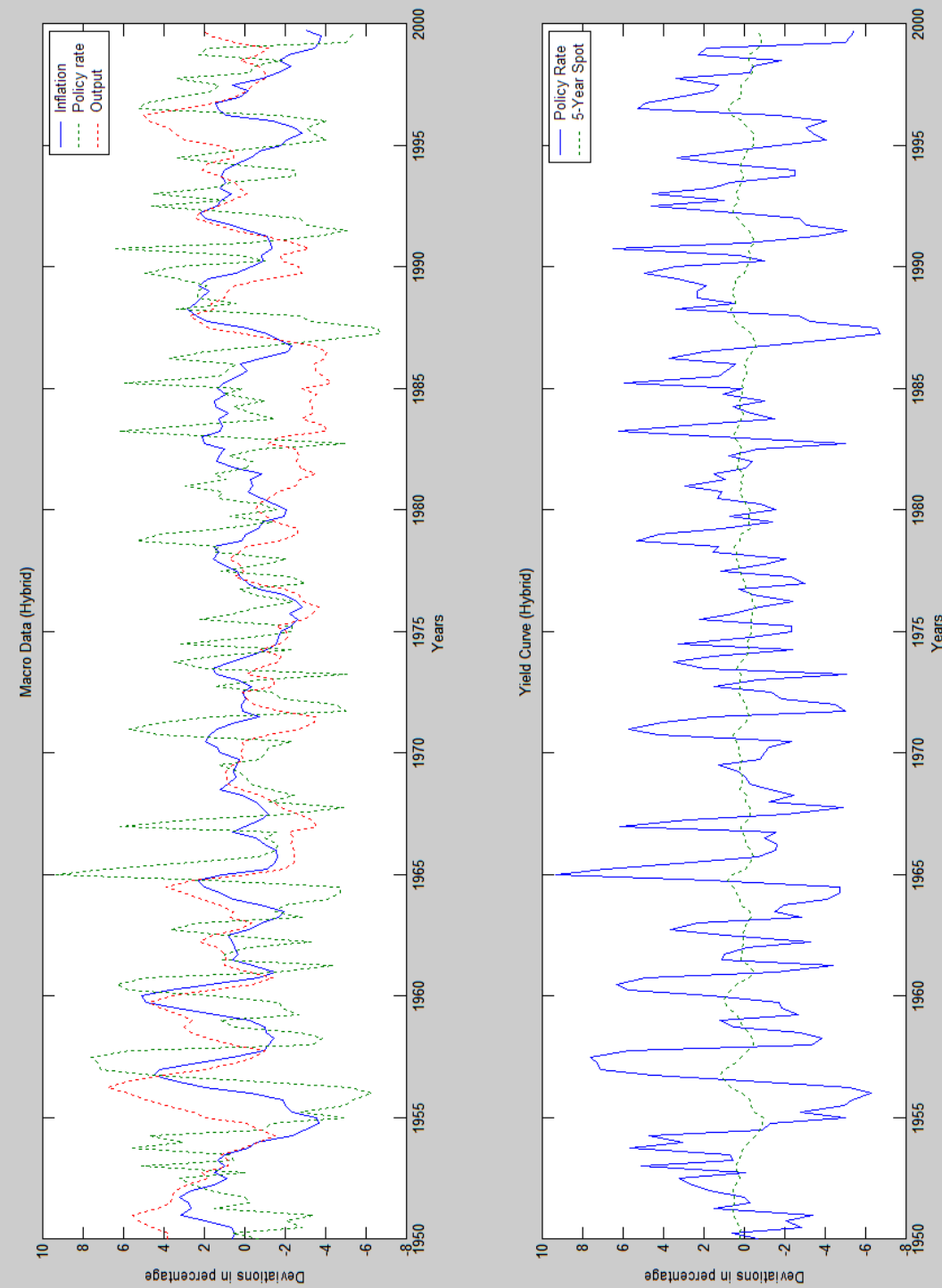

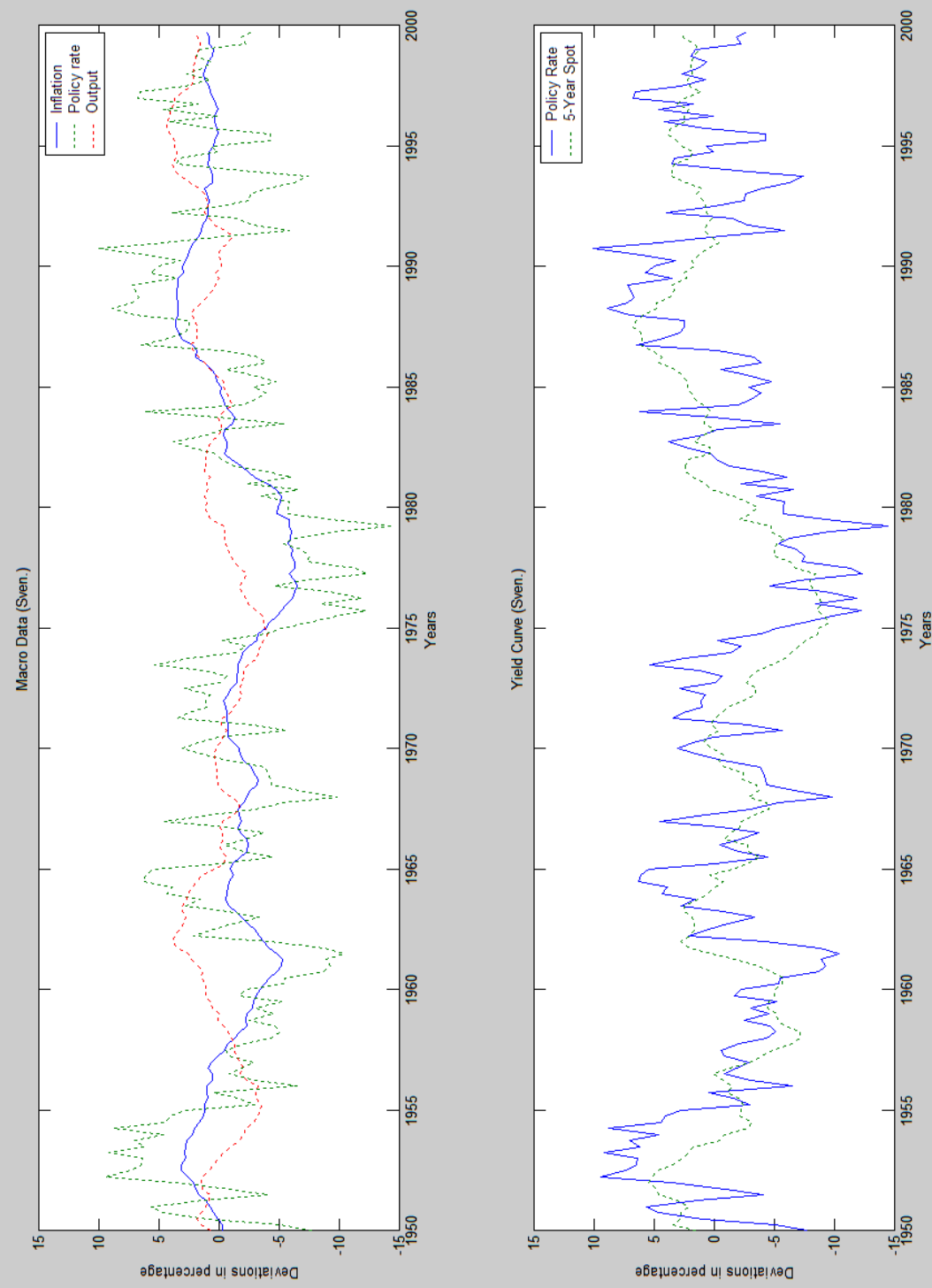


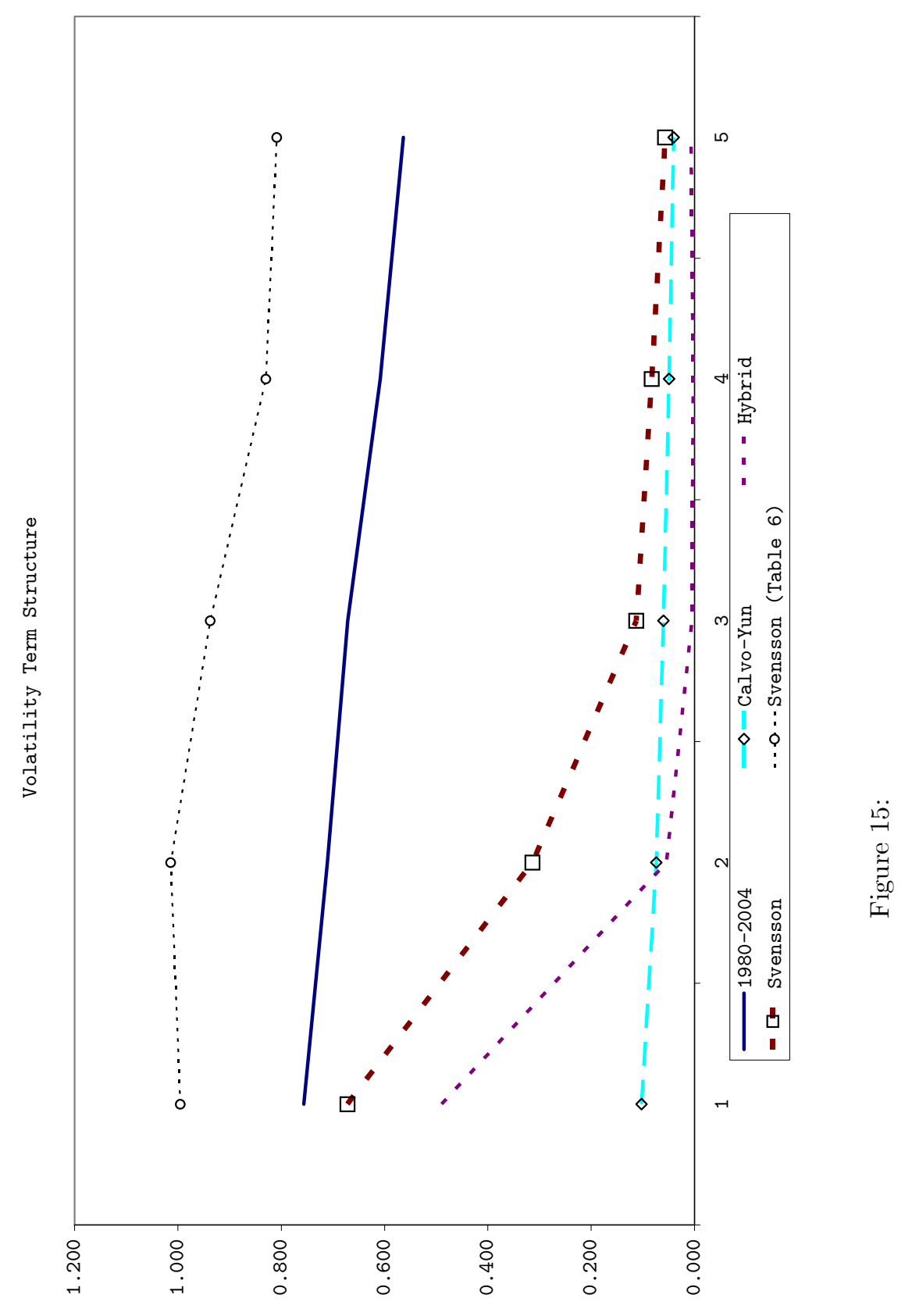

